\title{
Response of RC panels accounting for crack development and its interaction with rebars
}

\section{Eckart Hars}

Technical expert for maintenance planning, Swiss Federal Road Authority, Thoune, Switzerland (Orcid:0000-0001-8993-6937)

\section{Filip Niketić}

Research assistant and PhD candidate, École Polytechnique

Fédérale de Lausanne, Lausanne, Switzerland (corresponding author:

filip.niketic@epfl.ch) (Orcid:0000-0001-9106-1674)

\section{Miguel Fernández Ruiz}

Lecturer and senior scientist, École Polytechnique Fédérale de Lausanne, Lausanne, Switzerland (Orcid:0000-0001-6720-8162)

The response of reinforced concrete (RC) elements subjected to in-plane shear and axial stresses is governed by various potential failure mechanisms. For structural panels subjected to uniform stress states, their ultimate strength can be governed by yielding of the reinforcement, crushing of the concrete struts, sliding along a failure plane or spalling of the concrete cover. Although some expressions have been proposed in the literature to address this issue, they normally are empirical or semi-empirical in nature and do not distinguish among the failure mechanisms and their interaction. The purpose of this paper is to derive a mechanically-based efficiency factor for concrete in compression that is able to predict the actual behaviour of structural cracked concrete. This approach is shown to suitably predict the various potential failure modes and the development of the secondary shear cracks as well as the interaction between the reinforcement and the concrete.

\section{Notation}

$b_{\mathrm{w}} \quad$ thickness of analysed panel

$c \quad$ concrete cover

$D_{\max } \quad$ maximum aggregate diameter

$E_{\mathrm{s}} \quad$ Young's modulus of elasticity of steel

$F \quad$ applied force

$f_{\mathrm{c}} \quad$ concrete compressive strength

$f_{\text {cc }} \quad$ confined concrete strength

$f_{\text {ce }} \quad$ effective cylinder concrete compressive strength

$f_{\text {ctm }} \quad$ tensile concrete strength

$f_{\mathrm{y}} \quad$ steel yield strength

$h \quad$ size of panel in $z$-direction

$l \quad$ size of panel in $x$-direction

$l_{\mathrm{cr}, \mathrm{i}} \quad$ length of initial crack

$l_{\text {dow }} \quad$ dowelling length

$M \quad$ applied bending moment

$M_{\text {dow }} \quad$ dowelling moment of plastic hinge

$M_{\mathrm{p}} \quad$ maximum bending moment carried by a rebar

$N \quad$ normal force

$N_{\text {dow }} \quad$ normal force in plastic hinge

$N_{\mathrm{p}}$

$R$

$S_{\mathrm{rm}}$

$s_{x}, s_{z}$

$s_{\tau}$

$V_{\text {dow }}$

$V_{x z}$

$w$

$w_{\text {ini }}$

$\alpha$

$\delta$

$\Delta$

$\rho$

maximum axial force carried by a rebar reaction force

average initial crack spacing

spacing between rebars in $x$ - and $z$-directions

relative amount of damaged struts

dowelling shear force taken by a rebar

applied shear force

crack width

initial crack width

rebar tilting due to dowelling

slip of plastic hinge

rebar elongation due to dowelling $\theta_{\mathrm{cr}}$

$\theta_{\text {ult }}$

$\sigma$

$\sigma_{\mathrm{c}}$

$\sigma_{\mathrm{cc}}$

$\sigma_{i, \mathrm{ult}}$

$\sigma_{i}, \mathrm{y}$

average strain in $i$-direction

steel strain

effectiveness factor for concrete brittleness

effectiveness factor considering the presence of reinforcement

effectiveness factor considering induced transverse strains

effectiveness factor considering the presence of initial cracks

direction of principal compressive stress (and strain) initial crack inclination

ultimate crack inclination

reinforcement ratio

applied stress

stress in concrete

effective confined concrete strength

applied stress in $i$-direction at failure

applied stress in $i$-direction at the moment of first yielding

$\sigma_{\mathrm{s}} \quad$ stress in steel

$\sigma_{\mathrm{s}, \mathrm{cr}} \quad$ stress in steel at the point of cracking

$\tau \quad$ applied shear stress

$\tau_{\mathrm{b}} \quad$ reinforcement bond stress

$\tau_{\mathrm{cr}} \quad$ shear stress transferred though a crack

$\tau_{i j} \quad$ applied shear stress

$\phi \quad$ rebar diameter

\section{Introduction}

One of the most significant challenges in the analysis of structural concrete elements is related to the fact that the resistance of a member depends on its state of strains and is thus 
gradually changing as the load level increases. In order to predict a realistic response, it is therefore crucial to investigate the dependency of the various load-carrying actions on the state of the strains as well as their interaction.

With respect to linear members (refer to Figure 1), it is clear that the state of stresses of the web and the two flanges are quite different. In the flanges, both materials (concrete and steel) are predominantly subjected to uniform tension or compression. The web, however, transfers shear, which requires simultaneous activation of the reinforcement in tension and concrete in compression. Activation of the reinforcement generates additional cracking and bond stresses associated with tangential tensile stresses (Tepfers, 1979). In addition, disturbance is created by the local dowelling of the bars and the discontinuities introduced by the presence of the bars (Muttoni et al., 2006), reducing both the compressive strength and deformation capacity of concrete. Another important issue of the response of a panel is that, depending on the angle between the cracks and the direction of the principal compressive stress, the resistance of the material changes. The surface of the cracks is rough, which means that the average concrete compressive strength depends on the amount of stress that can be transferred by interface roughness. Given the fact that cracks are never perfectly parallel to each other and that they are actually unevenly spaced, local eccentricities appear inside the concrete struts, which can additionally reduce their strength.

Many experimental programmes have been conducted in attempts to better understand this complex problem (André, 1987; Belarbi and Hsu, 1995; Hsu and Zhang, 1997; Kirschner, 1986; Kollegger and Mehlhorn, 1990; Marti and Meyboom, 1992; Pang and Hsu, 1995; Schäfer et al., 1990; Vecchio and Chan, 1990; Vecchio and Collins, 1982; Vecchio et al., 1994; Watanabe and Muguruma, 1989; Zhang and Hsu, 1998), and the results from these studies are now incorporated in most modern codes of practice such as ACI 318-08 (ACI, 2008), Eurocode 2 (CEN, 2004) and the fib Model Code 2010 ( $f i b, 2011)$, as well as in non-linear numerical methods. Usually, this phenomenon is accounted for by means of

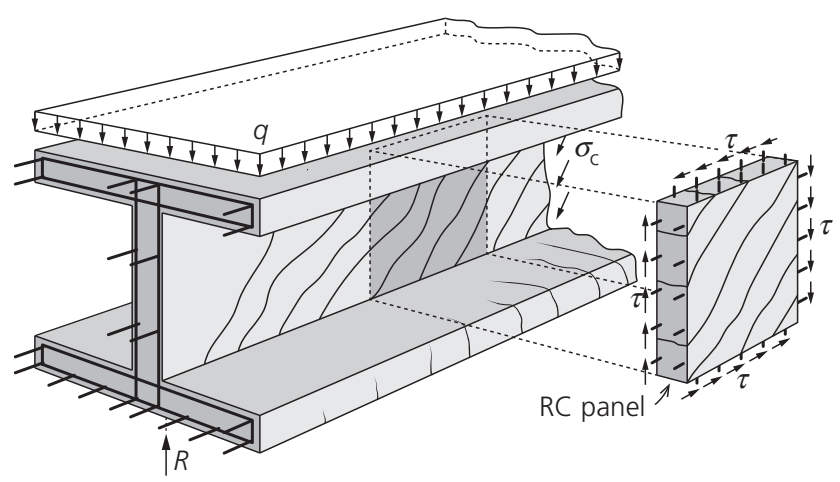

Figure 1. RC beam and web panel subjected to shear a strength reduction factor for concrete, which depends upon the cracking state and reduces the uniaxial strength of concrete.

In general, the two fundamental approaches used to address this problem are as follows.

To fix the angle of the cracks in the element and limit the amount of compressive stress that can be transferred through such cracks. These are referred to as fixed crack models as proposed by, for example, Okamura and Maekawa (1991).

- To assume that the inclination of the crack is always parallel to the principal compressive stress direction (thus being free to rotate) while limiting the strength of concrete as a function of the acting tensile strains. These are known as rotating crack models.

One of the most commonly used expressions for limiting the concrete compressive strength in the rotating crack model approach is that proposed by Vecchio and Collins (1986) as part of the modified compression field theory (MCFT). This expression is

1. $\eta_{\varepsilon}=\frac{1}{0 \cdot 8+170 \varepsilon_{1}}$

where $\varepsilon_{1}$ is the average principal tensile strain of the structural panel.

This approach has been shown to be simple and robust for design and assessment, and can be easily implemented in a numerical manner (Fernández Ruiz and Muttoni, 2007; Muttoni et al., 2015).

Other softening equations have been proposed by Belarbi and Hsu (1995), Kaufmann and Marti (1998) and Hars (2006). Vecchio (2000) derived another approach for dealing with shear failures of structural panels. Called the disturbed stress field model, the assumption of parallelism between the principal concrete stresses and strains is disregarded. Instead, the principal stresses turn after the principal concrete strains. The reduction of concrete compressive strength is still dependent on the average principal tensile strains.

Despite the fact that the compression softening equation of Vecchio and Collins (1986) suitably predicts experimental evidence, it is actually semi-empirical and does not distinguish between the various potential failure modes of (refer to Figure 2)

crushing of the concrete strut

- sliding of the concrete

- spalling of the concrete cover. 


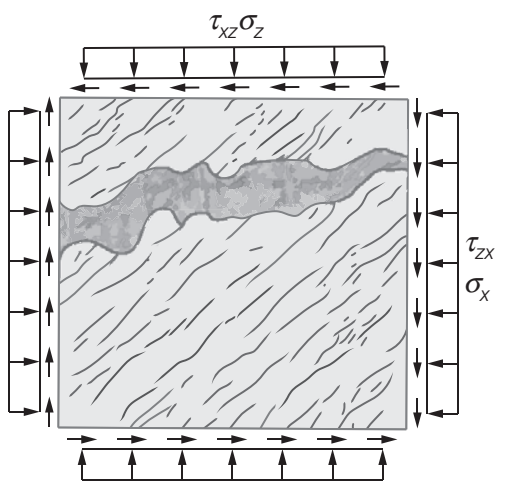

(a)

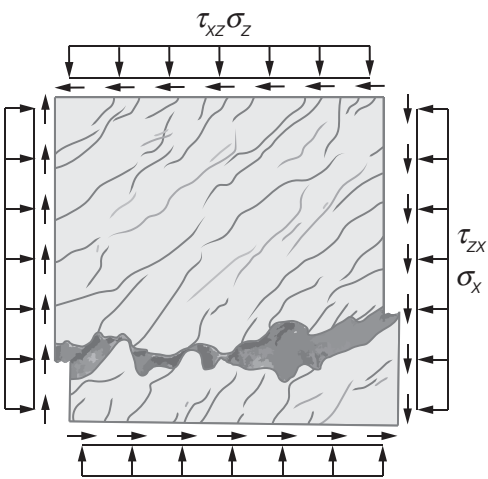

(b)

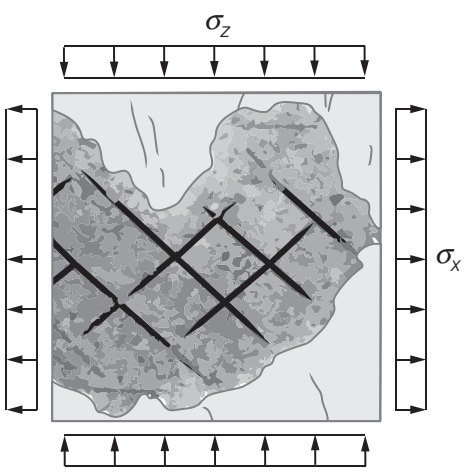

(c)

Figure 2. Failure mechanisms of RC panels tested by Kollegger and Mehlhorn (1990): (a) crushing of panel PK07; (b) sliding of panel PK02; (c) concrete cover spalling of panel EGE6F4

This does not allow designers to suitably understand the mechanisms governing failure and their interaction, or how to enhance the behaviour in the most effective manner.

The purpose of this paper is to provide a mechanical approach to assess the concrete compressive strength efficiency factor by taking into account the actual behaviour of structural panels and the interactions between steel and concrete. The consistency of the approach is validated by means of extensive comparisons with available test data, and the formulation is used to understand the relationship and dependency among the various mechanical parameters implied.

\section{Mechanical model for compression softening in reinforced concrete ( $R C)$ panels}

The response of an RC panel subjected to shear and/or to biaxial tension/compression can be described by analysing three physical stages (Figure 3).

- The first stage corresponds to a load transfer action valid up to first cracking of the panel (Figure 3(a)).

- The second stage (Figure 3(b)) describes behaviour that is applicable between first cracking of the panel and yielding of the reinforcement in one direction (this phase is also valid in the case where a panel fails prior to yielding of any steel).

- The third and final stage (Figure 3(c)) covers the loading history between yielding of the reinforcement in one direction and failure of the panel (due to crushing of the concrete or yielding of the reinforcement in both directions).

\section{Stages of behaviour}

The behaviour of a panel is characterised for an element as shown in Figure 4(a). The notations indicated in Figures 4(b) and 4(c) are used to refer to the stress and strain states, respectively.

\section{First stage: Linear elastic response}

During the early phases of loading, a RC panel can be analysed assuming linear elastic behaviour. Once the tensile strength of concrete is reached, cracks start to develop (Figure 3(a)). As the direction of the principal tensile strains can be assumed to be parallel to the principal tensile stresses for the elastic response, the stress state, strain state and the initial cracking angle $\left(\theta_{\mathrm{cr}}\right)$ are unambiguously defined (Figure 3(a)).

The amount of stress acting along the edge of a panel at any given point in the load history can be defined using the applied force as follows (refer to Figure 4(a)).

2. $\sigma_{x}=\frac{F_{x}}{h b_{\mathrm{w}}}=v_{x}$

3. $\sigma_{z}=\frac{F_{z}}{l b_{\mathrm{w}}}=v_{z}$

4. $\tau_{x z}=\frac{V_{x z}}{l h}=v_{x z}$

$F_{x}$ is the applied force in the $x$-direction, $F_{z}$ is the applied force in the $z$-direction, $V_{x z}$ is the applied shear force, $l$ is the size of the panel in the $x$-direction, $h$ is the size of the panel in the $z$ direction and $b_{\mathrm{w}}$ is the thickness of the panel.

Assuming that the panel behaves as a uniform elastic continuum up to cracking, one can calculate the principal tensile 


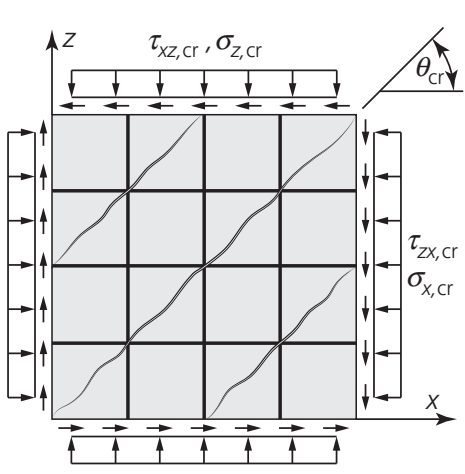

(a)
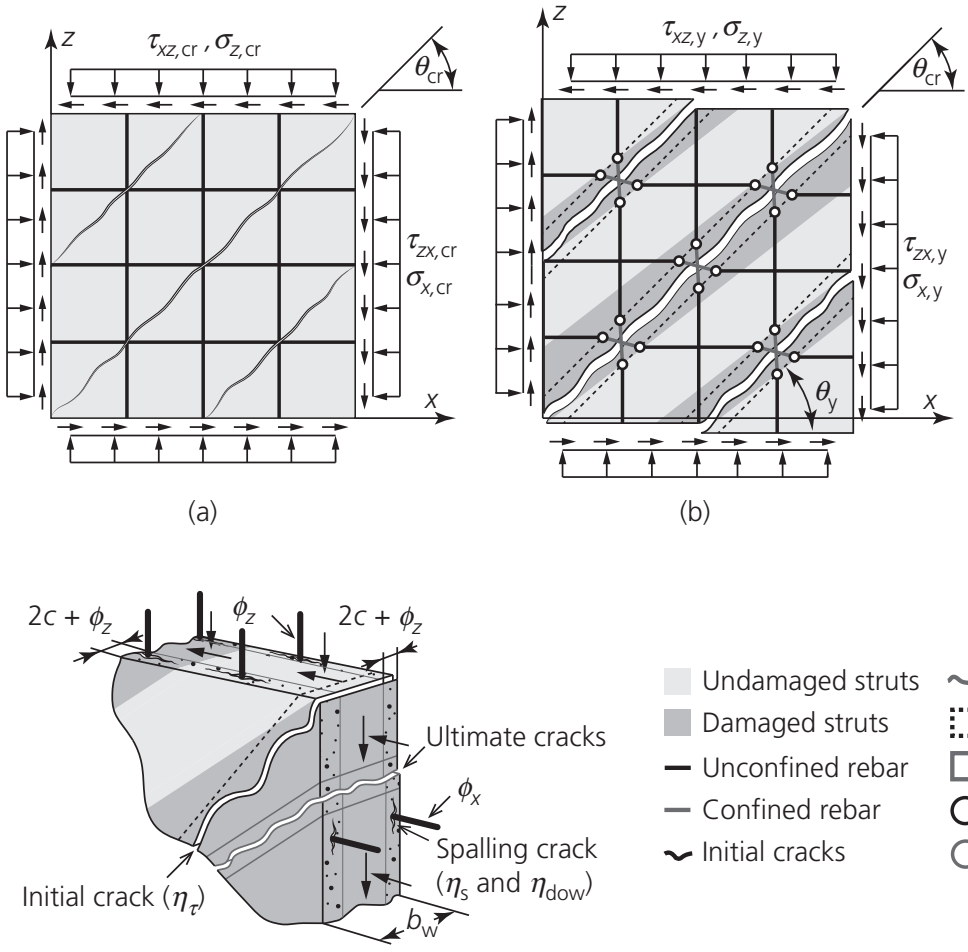

(b)

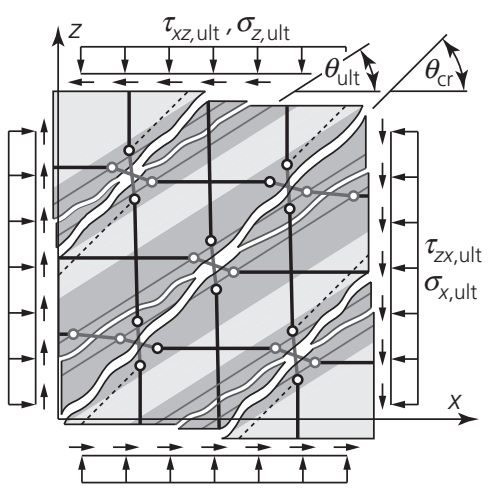

(c)

(d)

Figure 3. Modelling the physical behaviour of a RC panel subjected to shear and axial loads: (a) cracking point; (b) onset of yielding; (c) failure of the panel; (d) in-plane and out-of-plane reduction mechanism of concrete compressive strength

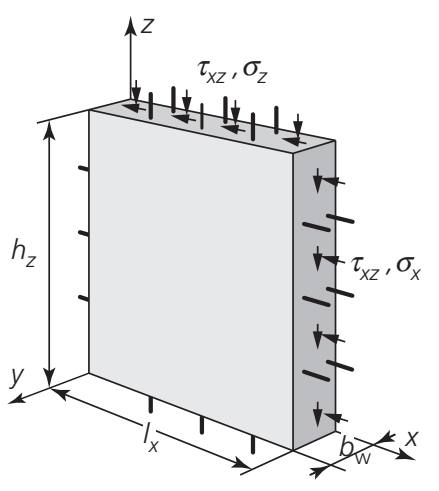

(a)

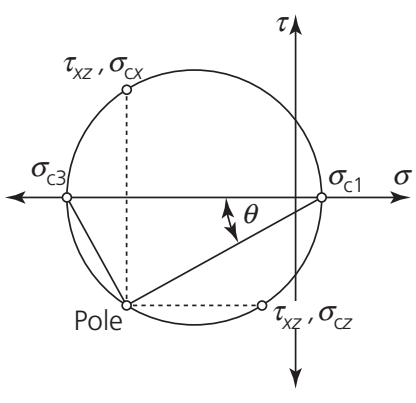

(b)

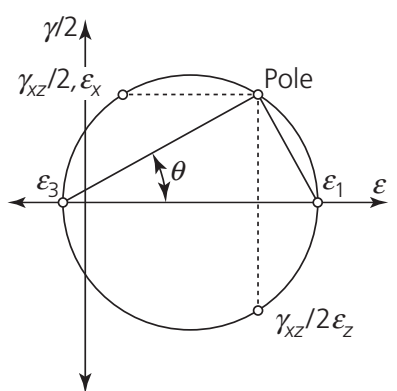

(c)

Figure 4. (a) Geometry and loading properties of an analysed panel. (b) Stress state of a concrete strut. (c) Average strain state of the panel

stress of the panel as

5. $\sigma_{\mathrm{c} 1}=\frac{v_{x}+v_{z}}{2}+\sqrt{\left(\frac{v_{x}-v_{z}}{2}\right)^{2}+v_{x z}^{2}}$

The limit case of the elastic phase is reached when the principal tensile stress becomes equal to the mean tensile strength of concrete $\left(\sigma_{\mathrm{c} 1}=f_{\mathrm{ctm}}\right)$. According to fib Model Code 2010
( $f i b, 2011)$, this can be estimated as

6. $f_{\mathrm{ctm}}= \begin{cases}0 \cdot 3\left(f_{\mathrm{c}}\right)^{2 / 3} & \text { for } f_{\mathrm{c}} \leq 50 \mathrm{MPa} \\ 2 \cdot 12 \ln \left(1+0 \cdot 1 f_{\mathrm{c}}\right) & \text { for } f_{\mathrm{c}}>50 \mathrm{MPa}\end{cases}$

where $f_{\mathrm{c}}$ is the uniaxial concrete compressive strength measured in a cylinder. 
The initial cracking angle can now be determined using Mohr's transformations (Figure 4(b)) as follows

$$
\text { 7. } \tan \theta_{\mathrm{cr}}=\frac{\sigma_{\mathrm{c} x}-\sigma_{\mathrm{c} 3}}{\tau_{x z}}
$$

\section{Second stage: Cracked behaviour}

The initial cracking angle remains unchanged throughout the second stage (as presented in Figure 3(b)). However, the direction of the principal compressive stresses starts to rotate in order to remain parallel to the principal compressive strains $\left(\theta_{\mathrm{y}}\right.$ in Figure 3(b)). This means that a portion of the concrete compressive struts, hereafter called the damaged struts, crosses the initial cracks (refer to Figure 3(b)). The strength of such struts is governed by aggregate interlocking occurring along the initial cracks. The remaining struts are considered as undamaged struts. Even though they are characterised by the absence of in-plane cracks, their strength is not equal to the concrete compressive strength determined from the standard cylinder test. This is justified, as the presence of the reinforcement induces the formation of spalling cracks, leading to out-of-plane failures (refer to Figure 3(d)). These spalling cracks limit the compressive strength of the concrete over a given portion of the panel's thickness (shown as the dotted areas in Figure 3(d)). This effect was taken into account based on the work of Hars (2006). The spalling reduction applies not only to the undamaged struts, but also to the damaged struts. In this manner, the strength of each strut is governed by the presence of in-plane and/or out-of-plane cracks.

The yield strength of the reinforcement is limited by the dowelling of the bars in the region near the cracks. As plastic hinges start to develop (indicated by the white circles in Figure 3(b)), the concrete between the surfaces of the cracks and the plastic hinges locally equilibrates the dowelling forces (shown as the light grey zones along the reinforcement in Figure 3(b)). This region, shown using dashed lines in Figure 3(b), which is partly developing in the undamaged and damaged struts, introduces a reduction in concrete strength due to the out-of-plane tensile stresses, potentially leading to spalling failures (presented in Figure 2(c)).

\section{Third stage: Behaviour after yielding}

The third and final stage is presented in Figure 3(c). At this point, a second family of cracks develops. Their inclination is parallel to the direction of the principal concrete compressive stress (and strain) at failure $\left(\theta_{\mathrm{ult}}\right)$. The presence of a second family of cracks causes additional dowelling of the reinforcement (plastic hinges activated at this phase are presented in Figure 3(c) using light grey circles). Given the fact that the direction of the principal compressive stress continues to rotate compared to the previous stage, the percentage of the surface corresponding to damaged struts increases and that of the undamaged struts decreases. The strength reduction mechanisms governing the strength of each type of concrete strut are methodologically the same as the previous stage. The stress field continues to rotate until the reinforcement in the other direction eventually reaches yielding or until the principal compressive stresses become equal to the effective concrete compressive strength.

\section{Plastic strength of the reinforcement accounting for dowelling forces and bar elongation}

As the initial and ultimate cracks start to open, the horizontal and vertical reinforcement of the panel is subjected to local bending. Consequently, plastic hinges start to develop in the vicinity of the crack faces (see Figures 3(b) and 3(c)), originating dowelling action. As the bar is dowelled, this reduces its capacity to carry tensile forces and determines the location at which plastic hinges will originate. Physical evidence of the dowelling action in RC panels has been reported by, for instance, Vecchio et al. (1994) in their experimental campaign. In addition to this, panels that have experienced sliding failures at the ultimate limit state (see Figure 2(b)) also show significant dowelling of the reinforcement.

The plastic stress distribution within a hinge at the ultimate limit state is presented in Figure 5(a). The central part of the

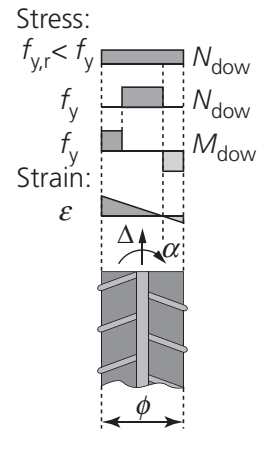

(a)

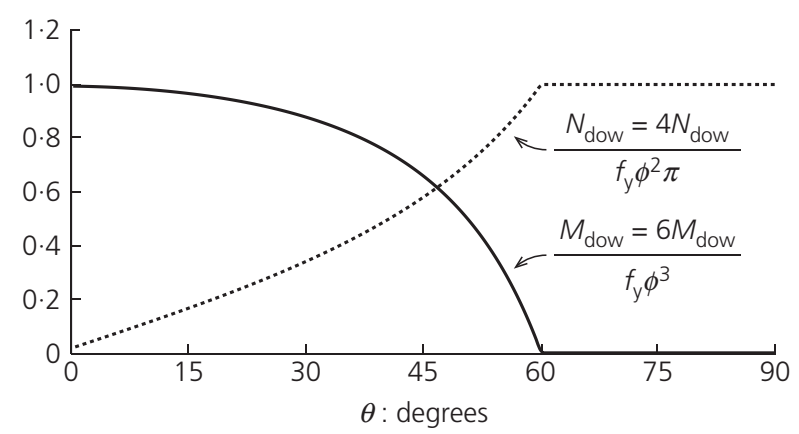

(b)

Figure 5. (a) Distribution of strains, stresses and internal force inside a plastic hinge of a rebar. (b) Axial strength reduction of horizontal rebar as a function of crack opening angle 
cross-section carries tension, while the rest carries the bending moment. In order to account for such interaction, the apparent yield strength of the steel in tension needs to be reduced $\left(f_{\mathrm{y}, \mathrm{r}}\right)$. It must be noted, however, that this detrimental effect of the dowelling in one direction $\left(f_{\mathrm{y}, \mathrm{r}}\right)$ brings some beneficial effects to the opposite direction $\left(V_{\text {dow }}\right)$, as presented in Figures $6(\mathrm{~d})$ and 6(e). This is justified as the bent rebar can resist some shear forces, reducing the amount of the force that has to be carried by the bars in the perpendicular direction. Depending on the inclination of the crack, the number of rebars that are actively contributing to carrying applied loads through the dowelling action can vary. When this angle is greater than $45^{\circ}$ (see Figure 6(d)), the number of rebars is governed by their spacing $\left(s_{x}\right.$ and $\left.s_{z}\right)$ and the height of the panel $(h)$, whereas if the angle is less than $45^{\circ}$ (Figure 6(e)) the number of rebars is determined based on the length of the panel $(l)$ and the spacing between rebars $\left(s_{x}\right.$ and $\left.s_{z}\right)$.

The development of tensile and dowel forces in a plastic hinge for a given crack direction and kinematics is investigated in Figure 6. The inclination of the initial crack is defined by $\theta_{\mathrm{cr}}$ and the direction of its opening by $\theta$. These two angles are considered to account for the fact that the crack is not necessarily (in all cases) parallel to the principal compressive stress and strain direction, and is therefore subjected to simultaneous opening and sliding. The plastic hinges are located at a distance to the crack called the dowelling length $\left(l_{\text {dow }}\right)$ (see Figure 6(a)). When the crack opens, the plastic hinges move horizontally and vertically from each other (refer to
Figure 6(b)). Since the rebar is not perfectly bonded to concrete, it slips for a value that can be expressed as function of the corresponding crack width. This is defined by the coefficient $\xi$ in Figure 6(c). Consequently, the rebar tilts (at a specific angle $\alpha$ ) and elongates for $2 \Delta$. Along the dowelling length, the rebar pushes against the surrounding concrete, transferring the dowelling forces to the concrete $\left(\sigma_{\mathrm{cc}}\right)$. According to Rasmussen (1962), the dowelling length for the case of dowelling with no eccentricity and no normal load can be estimated as

8. $l_{\mathrm{dow}}=\phi \sqrt{\frac{f_{\mathrm{y}}}{3 f_{\mathrm{cc}}}}$

where $l_{\text {dow }}$ is the dowelling length, $\phi$ is the diameter of the rebar, $f_{\mathrm{y}}$ is the initial yield strength of the rebar and $f_{\mathrm{cc}}$ is the concrete strength in a confining state.

Sorensen et al. (2016) state that, in the case of increased eccentricity and additional normal load, the dowelling length actually decreases, which reduces the moment contribution as well as the percentage of confining (i.e. damaged) struts within a panel (refer to Figures 3(b) and 3(c)). Therefore, the approach presented is slightly conservative.

The enhanced concrete strength equilibrating the dowelling forces can be estimated accounting for the influence of the concrete cover. Based on the work of Vintzeleou and Tassios

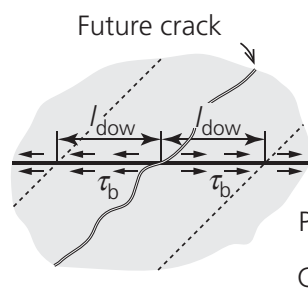

(a)

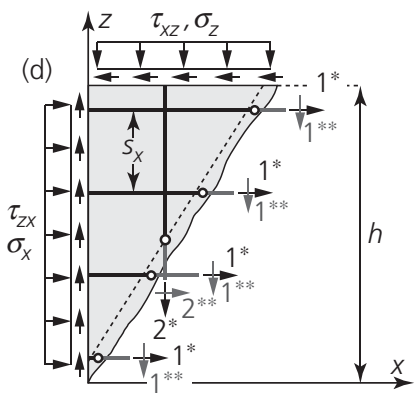

(d)

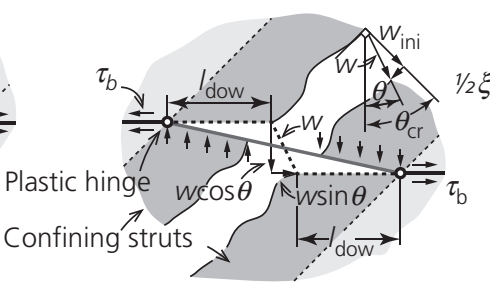

(b)

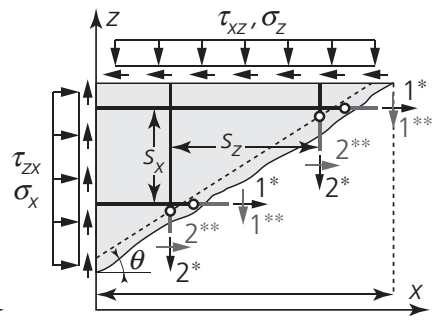

(e)

Figure 6. Dowelling mechanism of the reinforcement. (a) Location of the future plastic hinges and the initial crack. (b) Local bending of a horizontal rebar in the proximity of an initial crack - no slip along the rebar. (c) Local bending of a horizontal rebar in the proximity of an initial crack - accounting for the slip along the rebar. (d) Contributing rebars for crack angles greater than $45^{\circ}$. (e) Contributing rebars for crack angles less than $45^{\circ} .1^{*}, n_{x} f_{y x} ; 1^{* *}, V_{x, \text { dow }} ; 2^{*}, n_{z} f_{y z} 2^{* *}, V_{z, \text { dow }}$ 
(1990), the confined concrete strength can be estimated as

9. $f_{\mathrm{cc}}=f_{\mathrm{c}}\left[1+\frac{c_{1}}{\phi}\left(0.02 \frac{c_{2}}{\phi}+0 \cdot 15\right)\right]^{2} \leq 5 f_{\mathrm{c}}$

where $c_{1}$ is the concrete cover perpendicular to the confining concrete stress (cannot be larger than $4 \phi$ ) and $c_{2}$ is the concrete cover parallel to the confining concrete stress (cannot be larger than $8 \phi$ ).

On average, the corresponding values for the confined concrete strength are approximately equal to $3 \cdot 7 f_{\mathrm{c}}$. The actual concrete strength $\left(\sigma_{\mathrm{cc}}\right)$ is, however, determined at a later stage accounting for the actual dowelling moment in the rebar $\left(M_{\text {dow }}\right)$, and is always lower than $f_{\mathrm{cc}}$.

Relative rebar slip is estimated using an effective tie, as shown in Figures 7(b) and 7(c). Starting from the geometry of an analysed panel (Figure 7(a)), the crack spacing is estimated using the expression assuming a constant bond strength according to Marti et al. (1998)

10. $s_{\mathrm{rm}}=\frac{1}{\left(\sin \theta_{\mathrm{cr}} / s_{\mathrm{rm} x}\right)+\left(\cos \theta_{\mathrm{cr}} / s_{\mathrm{rm} z}\right)}$

11. $s_{\mathrm{rm} x}=\frac{3}{2}\left(\frac{1-\rho_{x}}{\rho_{x}}\right) \frac{\phi_{x}}{8}$

12. $S_{\mathrm{rm} z}=\frac{3}{2}\left(\frac{1-\rho_{z}}{\rho_{z}}\right) \frac{\phi_{z}}{8}$

where $\rho_{x}$ is the reinforcement ratio in the $x$-direction, $\phi_{x}$ is the diameter of the rebar in the $x$-direction, $\rho_{z}$ is the reinforcement ratio in the $z$-direction and $\phi_{z}$ is the diameter of the rebar in the $z$-direction.
The effective reinforcement ratio in the direction perpendicular to the direction of cracks (Figure 7(b)) is calculated from

13. $\rho_{\text {eff }}=\rho_{x} \sin ^{2} \theta_{\text {cr }}+\rho_{z} \cos ^{2} \theta_{\text {cr }}$

The effective rebar spacing is assumed to be equal to the average spacing of the horizontal and vertical reinforcement projected in the direction of the cracks, given by

14. $s_{\mathrm{eff}}=\frac{1}{2}\left(\frac{s_{x}}{\sin \theta_{\mathrm{cr}}}+\frac{s_{z}}{\cos \theta_{\mathrm{cr}}}\right)$

where $s_{x}$ is the spacing between rebars in the $x$-direction and $s_{z}$ is the spacing between the rebars in the $z$-direction.

Figure 7(c) shows the reinforcement strain distribution inside the effective tie at its cracking point and for a higher stress level. As can be seen in the figure, both strains are linearly varying between the two consecutive cracks (constant bond strength). Maximum steel strains $\left(\varepsilon_{\mathrm{s} 1}\right)$ are expected at the location of the crack while minimum steel strains $\left(\varepsilon_{\mathrm{s} 2}\right)$ are expected in the middle of the two consecutive cracks (concrete strains are neglected). These strains are given by

15. $\varepsilon_{\mathrm{s} 1}=\frac{\sigma_{\mathrm{s}}}{E_{\mathrm{s}}}$

16. $\varepsilon_{\mathrm{s} 2}=\frac{\sigma_{\mathrm{s}}}{E_{\mathrm{s}}}-\frac{2 \tau_{\mathrm{b}} s_{\mathrm{rm}}}{E_{\mathrm{s}} \phi_{\mathrm{eff}}}$

where $\sigma_{\mathrm{s}}$ is the stress in the reinforcement, $E_{\mathrm{s}}$ is the Young's modulus of elasticity, $\phi_{\text {eff }}$ is the effective rebar diameter (shown in Figure 7(b)) and $\tau_{\mathrm{b}}$ is the average bond stress, which can be estimated according to Marti et al. (1998) (for deformed rebars) from

17. $\tau_{\mathrm{b}}=2 f_{\mathrm{ctm}}$

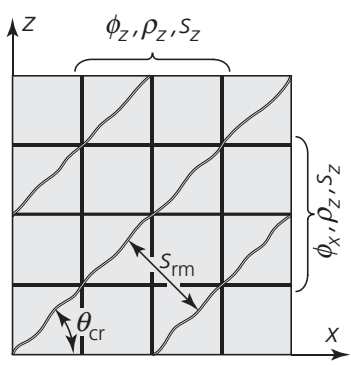

(a)

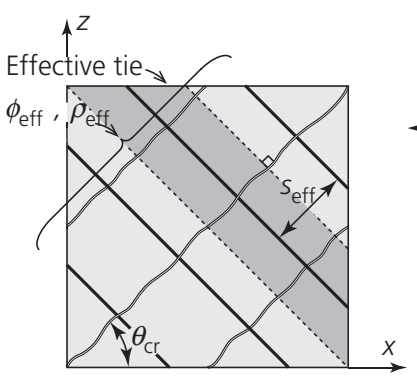

(b)

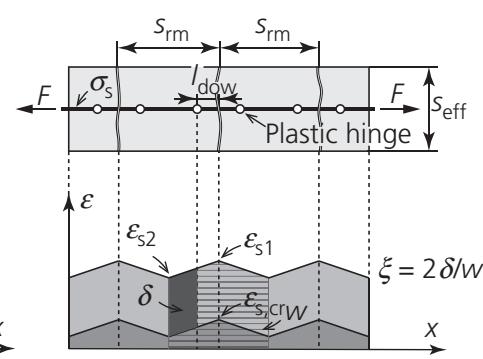

(c)

Figure 7. (a) Geometry of the reinforcement in horizontal and vertical directions. (b) Geometry of the effective reinforcement and effective tie. (c) Strain state along the effective tie 
where $f_{\text {ctm }}$ is the mean tensile concrete strength given in Equation 6.

In the case of smooth rebars, the bond law is calculated according to fib Model Code $2010(f i b, 2011)$ as

18. $\tau_{\mathrm{b}}=0 \cdot 15 \sqrt{f_{\mathrm{c}}}$

Plastic hinges are assumed to form at the cracking point of the panel in the vicinity of the initial cracks (as presented
Based on the mechanism given in Figure 6(a), the rebar tilting angle can be expressed as

24. $\alpha=\arctan \left(\frac{w \cos \theta}{2 l_{\text {dow }}+(1-\xi) w \sin \theta}\right)$

Returning to the same mechanism, the rebar elongation can be determined from

25. $\left(2 l_{\mathrm{dow}}+2 \Delta\right)^{2}=\left[2 l_{\mathrm{dow}}+(1-\xi) w \sin \theta\right]^{2}+(w \cos \theta)^{2}$

$$
\text { 26. } \Delta=\frac{1}{2} \sqrt{4 l_{\mathrm{dow}}^{2}+4 l_{\mathrm{dow}} w \sin \theta(1-\xi)+w^{2}\left[1-2 \xi(\sin \theta)^{2}+(\xi \sin \theta)^{2}\right]}-l_{\text {dow }}
$$

in Figure 7(c)). As the stress level increases in the rebar, the plastic hinges move towards the crack. The slip $(\delta)$ can be estimated by integrating the area hatched with lines in Figure 7(c). As presented in Figure 7(c), this value depends on the amount of steel stress $\left(\sigma_{\mathrm{s}}\right)$. A mean value between the steel stress at the point of cracking $\left(\sigma_{\mathrm{s}, \mathrm{cr}}\right)$ and the yield strength of the steel $\left(f_{\mathrm{y}}\right)$ is assumed, in other words

19. $\sigma_{\mathrm{s}}=\frac{\sigma_{\mathrm{s}, \mathrm{cr}}+f_{\mathrm{y}}}{2}$

20. $\sigma_{\mathrm{s}, \mathrm{cr}}=\frac{f_{\mathrm{ctm}}}{\rho_{\mathrm{eff}}}$ where $w$ is the total displacement, which can be estimated according to the mechanism presented in Figure 6(b) as

$$
\text { 27. } w=\frac{w_{\text {ini }}}{\cos \left(\theta_{\mathrm{cr}}-\theta\right)}
$$

where $w_{\text {ini }}$ is the initial crack width.

In order to estimate the amount of rebar dowelling based on crack kinematics, it is necessary to define the incremental difference of the rebar tilting angle and its elongation as a function of the crack opening. In other words, one needs to find the first derivatives of Equation 24 and 26

$$
\text { 28. } \quad \dot{\alpha}=\frac{\partial \alpha}{\partial w}=\frac{2 l_{\mathrm{dow}} \cos \theta}{4 l_{\mathrm{dow}}^{2}+4 l_{\mathrm{dow}} w \sin \theta(1-\xi)+w^{2}\left[1-2 \xi(\sin \theta)^{2}+(\xi \sin \theta)^{2}\right]}
$$

$$
\text { 29. } \dot{\Delta}=\frac{\partial \Delta}{\partial w}=\frac{2 l_{\text {dow }} \sin \theta(1-\xi)+w\left[1-2 \xi(\sin \theta)^{2}+(\xi \sin \theta)^{2}\right]}{2 \sqrt{4 l_{\text {dow }}^{2}+4 l_{\text {dow }} w \sin \theta(1-\xi)+w^{2}\left[1-2 \xi(\sin \theta)^{2}+(\xi \sin \theta)^{2}\right]}}
$$

The amount of slip itself can be estimated as

$$
\text { 21. } \delta=\frac{\sigma_{\mathrm{s}}-\sigma_{\mathrm{s}, \mathrm{cr}}}{E_{\mathrm{s}}}\left(\frac{s_{\mathrm{rm}}}{2}-l_{\mathrm{dow}}\right)
$$

In order to express the slip of a hinge in a more general manner (as a function of the corresponding crack width), the parameter $\xi$ is defined as

22. $\xi=\frac{2 \delta}{w}$

23. $w=s_{\mathrm{rm}} \frac{\varepsilon_{\mathrm{s} 1}+\varepsilon_{\mathrm{s} 2}}{2}$
The yield condition of the circular cross-section subjected to simultaneous tension and bending is similar to the one derived for a rectangular cross-section but far more complex (Sorensen et al., 2016), which is why the dowelling of the rebar is derived using the simpler expression (Nielsen and Hoang, 2011)

30. $f(N, M)=m+n^{2}-1=0$

31. $m=\frac{M}{M_{\mathrm{p}}}=\frac{6 M}{\phi^{3} f_{\mathrm{y}}}$

32. $n=\frac{N}{N_{\mathrm{p}}}=\frac{4 N}{\phi^{2} \pi f_{\mathrm{y}}}$ 
where $M$ is the bending moment acting on a rectangular crosssection and $N$ is the axial force acting on the rectangular crosssection.

Application of the normality condition of Equation 30 gives

33. $\dot{\alpha}=\lambda \frac{\partial f(M, N)}{\partial M}=\lambda \frac{\partial f(M, N)}{\partial m} \frac{\partial m}{\partial M}=\lambda \frac{1}{M_{\mathrm{p}}}$

34. $\dot{\Delta}=\lambda \frac{\partial f(M, N)}{\partial N}=\lambda \frac{\partial f(M, N)}{\partial n} \frac{\partial n}{\partial N}=\lambda 2 n \frac{1}{N_{\mathrm{p}}}$

where $\lambda$ is an integration factor.

After combining the Equations 28, 29, 33 and 34, it is possible to estimate the relative amount of axial tensile force in a rebar for given crack kinematics subjected to a pure normal force, the stress state of point B can be achieved through various strain profiles (see Figure 8(b)) since the neutral axis is always outside of the rebar cross-section. According to the rigid plastic approach, at point $\mathrm{B}$, it is therefore possible to have no moment but some level of curvature.

The maximum shear carried by dowelling can be calculated accounting for the pressure developed in the concrete (Figure 6(c))

\section{7. $V_{\text {dow }}=\phi l_{\text {dow }} \sigma_{\mathrm{cc}}$}

where $\sigma_{\mathrm{cc}}$ is the effective concrete pressure acting along the dowel length, which may be estimated from simple free-body equilibrium (Figure 6(c))

38. $\sigma_{\mathrm{cc}}=\frac{2 M_{\mathrm{dow}}}{\phi l_{\mathrm{dow}}^{2}}=\frac{m_{\mathrm{dow}} \phi^{2} f_{\mathrm{y}}}{3 l_{\mathrm{dow}}^{2}}$

35. $n_{\mathrm{dow}}=\left[\frac{3 \pi}{4 \phi} \frac{2 l_{\mathrm{dow}} \sin \theta(1-\xi)+w\left[1-2 \xi(\sin \theta)^{2}+(\xi \sin \theta)^{2}\right]}{4 l_{\mathrm{dow}} \cos \theta}\right] \sqrt{4 l_{\mathrm{dow}}^{2}+4 l_{\mathrm{dow}} w \sin \theta(1-\xi)+w^{2}\left[1-2 \xi(\sin \theta)^{2}+(\xi \sin \theta)^{2}\right]}$

Once the amount of axial tensile force in a rebar is determined, the amount of moment can be expressed as

36. $m_{\text {dow }}=1-n_{\text {dow }}^{2}$

The distribution of these two parameters $\left(n_{\mathrm{dow}}\right.$ and $\left.m_{\mathrm{dow}}\right)$ can be seen in Figure 5(b) as a function of the crack opening angle. As can be seen, the maximum amount of moment is obtained for $\theta=0^{\circ}$. At this angle, the crack opens perpendicularly to the rebar. For a general case (see point $\mathrm{A}$ in Figures 8(a) and 8(b)), the neutral axis is inside the analysed rebar, which means that part of the cross-section is subjected to uniform compression while the rest is subjected to uniform tension. When the bar is
The total force carried by the dowelling can thus be calculated on the basis of Figures 6(d) and 6(e) by adding the contribution of each bar $\left(V_{\text {dow }}\right)$ for the total number of bars intersected by cracks.

\section{Concrete strength limitations}

The effective concrete compressive strength of the analysed panel can be expressed by combining the resistances of the two types of struts (damaged and undamaged) presented in Figure 9(a) in the following manner.

\section{9. $f_{\mathrm{ce}}=f_{\mathrm{c}} \eta_{\mathrm{fc}}\left[\eta_{\mathrm{DS}} s_{\tau}+\eta_{\mathrm{UDS}}\left(1-s_{\tau}\right)\right]$}

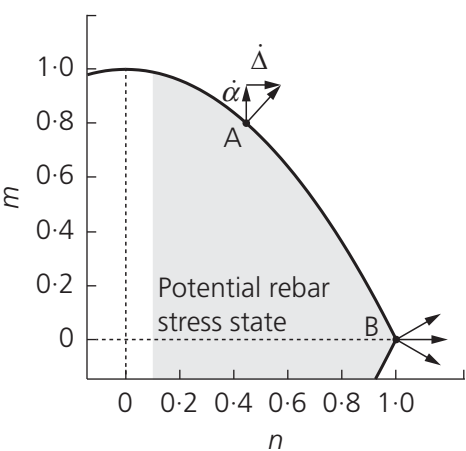

(a)
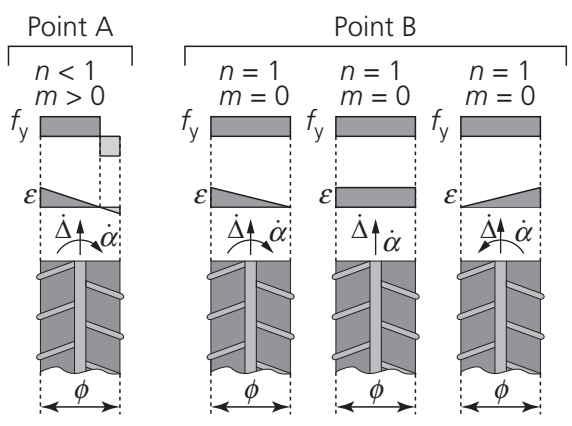

(b)

Figure 8. (a) Moment-normal force interaction diagram. (b) Distribution of strains and stresses in a rebar 


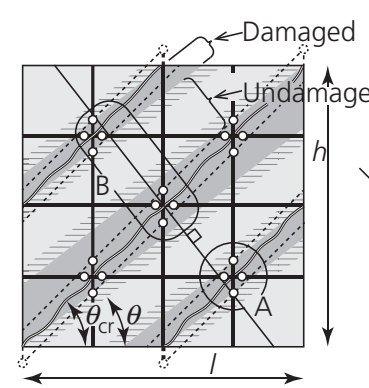

(a)

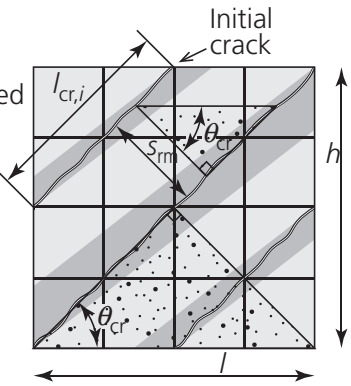

(b)

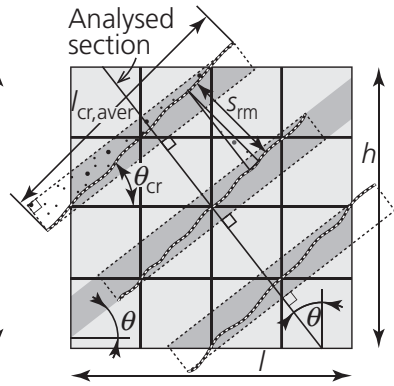

(c)

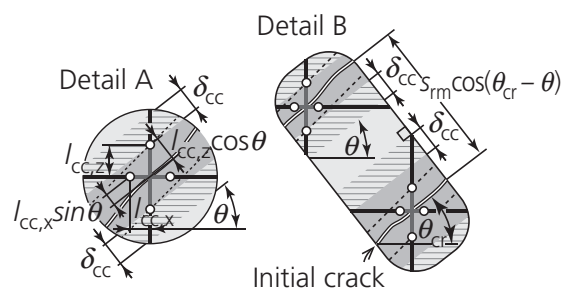

Undamaged struts - no confinement

E Undamaged struts - confinement

Damaged struts

O Plastic hinges

$\approx$ Real cracks

Fictitious cracks

(d)

Figure 9. (a) Surface quantity and distribution of damaged and undamaged struts in a panel. (b) Number of initial cracks in a panel. (c) Effective damaged strut length and width. (d) Details determining the confining concrete strut width

$f_{\mathrm{c}}$ is the uniaxial concrete compressive strength measured in a cylinder, $s_{\tau}$ is the relative amount of damaged struts in the panel, $\eta_{\mathrm{DS}}$ is the effectiveness factor for the compressive strength of damaged struts and $\eta_{\text {UDS }}$ is the effectiveness factor for the compressive strength of undamaged struts.

The parameter $\eta_{\mathrm{fc}}$ is an effectiveness factor that accounts for the brittle behaviour of concrete in compression. The original expression for $\eta_{\mathrm{fc}}$ was proposed by Muttoni (1989) and is currently incorporated in fib Model Code 2010 (fib, 2011) for calculation of the compressive strength of concrete in shear

40. $\quad \eta_{\mathrm{fc}}=\sqrt[3]{\left(\frac{30}{f_{\mathrm{c}}}\right)} \leq 1.0$

This factor allows one to account for the internal redistributions of stress occurring in the panel.

The relative amount of damaged (and consequently undamaged) struts in the analysed panel depends on the length of the initial cracks (which can be seen in Figures 9(a) and 9(b)). In order to account for their uneven length, an effective (average) crack length is calculated based on geometrical considerations from Figure 9(b)

41. $l_{\mathrm{eff}}=\left(\frac{l-0 s_{\mathrm{rm} x}}{\cos \theta_{\mathrm{cr}}}+2 \frac{l-1 s_{\mathrm{rm} x}}{\cos \theta_{\mathrm{cr}}}+2 \frac{l-2 s_{\mathrm{rm} x}}{\cos \theta_{\mathrm{cr}}}+\cdots+2 \frac{l-n s_{\mathrm{rm} x}}{\cos \theta_{\mathrm{cr}}}\right) / 2 n+1 l_{\mathrm{eff}}=\frac{l}{\cos \theta_{\mathrm{cr}}}-\frac{s_{\mathrm{rm}}}{\sin \theta_{\mathrm{cr}} \cos \theta_{\mathrm{cr}}}\left(\frac{n(n+1)}{2 n+1}\right)$

where $n$ can be calculated as

42. $n=\frac{l \sin \theta_{\mathrm{cr}}}{s_{\mathrm{rm}}}$
Combining Equations 41 and 42 yields

43. $l_{\mathrm{eff}}=\frac{l}{\cos \theta_{\mathrm{cr}}}\left(\frac{n}{2 n+1}\right)$

Finally, the relative amount of damaged struts in the analysed section can be estimated (indicated in Figure 9(c)) by

44. $s_{\tau}=\frac{n^{\prime} l_{\mathrm{eff}} \sin \left(\theta_{\mathrm{cr}}-\theta\right) \cos \theta}{h}$

45. $\quad n^{\prime}=\frac{h \cos \left(\theta_{\mathrm{cr}}-\theta\right)}{\cos \theta s_{\mathrm{rm}}}+1$

where $n^{\prime}$ is the effective number of damaged struts, $s_{\mathrm{rm}}$ is the average initial crack spacing, $l$ is the size of the analysed panel in the $x$-direction and $h$ is the size of the analysed panel in the $z$-direction.

\section{Strength of the damaged struts}

The compressive strength of the damaged struts is limited by the parameter $\eta_{\mathrm{DS}}$, which takes into account 
- the presence of the initial cracks crossing the damaged struts, governing the in-plane element failures $\left(\eta_{\tau}\right.$, which will be defined later in the paper)

- the interaction between the in-plane and out-of-plane element failures (adopted from Hars (2006))

- the presence of dowelled rebars ( $\eta_{\text {dow }}$, which will be defined later in the paper).

The value of the effectiveness factor for the compressive strength of the damaged struts can thus be calculated as

46. $\quad \eta_{\mathrm{DS}}=\min \left\{\begin{array}{c}\frac{\eta_{\tau} \max \left\{\begin{array}{c}\eta_{\mathrm{s}} \\ b_{\mathrm{w}}-\left(4 c+2 \phi_{\mathrm{ext}}\right)\end{array}\right\}}{b_{\mathrm{w}}} \\ +\frac{\eta_{\tau} \min \left\{\begin{array}{c}b_{\mathrm{w}} \\ 4 c+2 \phi_{\mathrm{ext}}\end{array}\right\}}{b_{\mathrm{w}}}\left(1-\eta_{\mathrm{dow}} \delta_{\mathrm{s}}\right)\end{array}\right.$

where $\eta_{\mathrm{s}}$ is an effectiveness factor that accounts for the presence of the reinforcement in concrete (out-of-plane failure), $\eta_{\tau}$ is an effectiveness factor that accounts for the presence of the initial cracks in concrete (in-plane-failure), $\eta_{\text {dow }}$ is a factor that takes into account the presence of rebars pressing against the concrete due to the dowelling (see Figure 3(c) and (d)), $\delta_{\mathrm{s}}$ is the ratio between the external rebar diameter and the sum of twice the concrete cover thickness and the external rebar diameter, $b_{\mathrm{w}}$ is the thickness of the panel, and $c$ is the concrete cover thickness.

With respect to Equation 46, it can be seen that the resistance of a damaged strut is limited either by the presence of out-of-plane cracks (considered by means of the coefficient $\eta_{\mathrm{s}}$ ) or by the presence of in-plane cracks (considered by means of the coefficient $\left.\eta_{\tau}\right)$ combined with the dowelling of the reinforcement $\left(\eta_{\text {dow }}\right)$.

The effectiveness factor that accounts for the presence of reinforcement in concrete $\left(\eta_{\mathrm{s}}\right)$ was developed on the basis of the work of Hars (2006). Reinforcement bars introduce local defects into the concrete cover region, which may cause it to spall off (see the dotted strips in Figure 3(d)), while the rest of the section remains undisturbed. This effect is physically governed by the out-of-plane cracks (called spalling cracks in Figure 3(d)) and can be quite pronounced in the case of heavily reinforced concrete panels. On the basis of the work of Hars (2006), it is proposed that the effectiveness factor that accounts for the presence of the reinforcement in concrete $\left(\eta_{\mathrm{s}}\right)$ is evaluated as

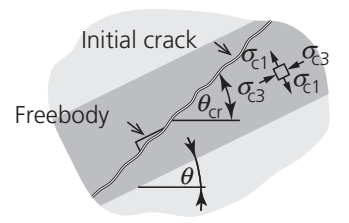

(a)

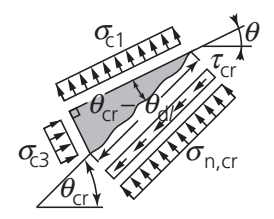

(b)

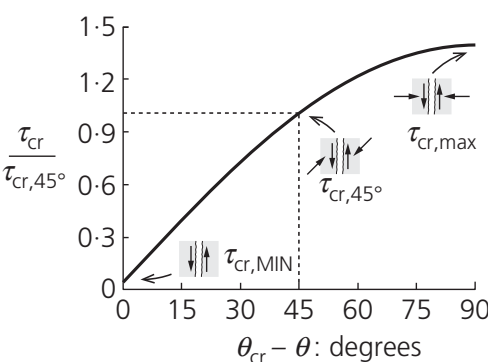

(c)

Figure 10. (a) Stress state of a damaged strut and inclination of an initial crack. (b) Stresses acting along the sides of the analysed free body. (c) Shear stresses acting along the crack surface as a function of the stress field rotation angle

49. $\delta_{\mathrm{s}}=\frac{\phi_{\text {ext }}}{2 c+\phi_{\text {ext }}}$

50. $\phi_{\mathrm{s}}= \begin{cases}\arctan 0.6 & \text { for plain reinforcement bars } \\ \arctan 1.0 & \text { for ribbed reinforcement bars }\end{cases}$

Here, $c$ is the concrete cover, $s_{\text {ext }}$ is the distance between external reinforcement bars, $\phi_{\text {ext }}$ is the external rebar diameter and $\omega_{\mathrm{s}}$ is the local stress field disturbance ratio.

It should be noted that Equation 48 gives the expression for $\omega_{\mathrm{s}}$ assuming that the external reinforcement is in the vertical direction. In the case where a horizontal rebar is closer to the panel's surface, $\cos \theta$ should be replaced by $\sin \theta$ in Equation 48.

As already mentioned, the effectiveness factor that accounts for the presence of the initial cracks in concrete $\left(\eta_{\tau}\right)$ limits the strength of the damaged concrete struts. This coefficient is estimated based on the amount of shear stress that can be transferred through the initial crack. By investigating a free body (Figures 10(a) and 10(b)), the equilibrium of forces acting along each side of the free body in the direction of the initial crack $\left(\theta_{\text {cr }}\right)$ can be obtained as

47. $\quad \eta_{\mathrm{s}}=\frac{\max \left\{\begin{array}{c}0 \\ b_{\mathrm{w}}-\left(4 c+2 \phi_{\mathrm{ext}}\right)\end{array}\right\}}{b_{\mathrm{w}}}+\frac{\min \left\{\begin{array}{c}b_{\mathrm{w}} \\ 4 c+2 \phi_{\mathrm{ext}}\end{array}\right\}}{b_{\mathrm{w}}}\left\{\frac{f_{\mathrm{c}}^{2}}{225}\left[1+\frac{4 \omega_{\mathrm{s}}^{2}}{\delta_{\mathrm{s}}\left(1-\sin \phi_{\mathrm{s}}\right)}\left(\frac{1-\delta_{\mathrm{s}}\left(1-\sin \phi_{\mathrm{s}}\right)}{1-\delta_{\mathrm{s}}}\right)^{2}\right]^{-1}+\frac{1}{1-\delta_{\mathrm{s}}\left(1-\sin \phi_{\mathrm{s}}\right)}\right\}^{-1}$

48. $\omega_{\mathrm{s}}=\min \left\{\frac{s_{\mathrm{ext}}-\phi_{\mathrm{ext}}^{1 \cdot 5}}{2 \cos \theta} \frac{1}{2 c+\phi_{\mathrm{ext}}}\right\}$

51. $\sigma_{\mathrm{c} 3} \sin \left(\theta_{\mathrm{cr}}-\theta\right) \cos \left(\theta_{\mathrm{cr}}-\theta\right)+\sigma_{\mathrm{c} 1} \cos \left(\theta_{\mathrm{cr}}-\theta\right) \sin \left(\theta_{\mathrm{cr}}-\theta\right)=\tau_{\mathrm{cr}}$ 
Expressing the principal concrete compressive strength from Equation 51

52. $\sigma_{\mathrm{c} 3}=\frac{2 \tau_{\mathrm{cr}}}{\sin \left(2\left(\theta_{\mathrm{cr}}-\theta\right)\right)}-\sigma_{\mathrm{c} 1}$

Since the concrete strength in this free body is limited by the amount of shear stress that can be transferred through a crack and the brittleness of the concrete

53. $\sigma_{\mathrm{c} 3}=f_{\mathrm{c}} \eta_{\mathrm{fc}} \eta_{\tau}$

The effectiveness factor that accounts for the presence of the initial cracks in concrete (in-plane failure) is then estimated as

54. $\quad \eta_{\tau}=\frac{2 \tau_{\mathrm{cr}}}{f_{\mathrm{c}} \eta_{\mathrm{fc}} \sin \left(2\left(\theta_{\mathrm{cr}}-\theta\right)\right)}-\frac{\sigma_{\mathrm{c} 1}}{f_{\mathrm{c}} \eta_{\mathrm{fc}}} \leq 1$

where $\tau_{\mathrm{cr}}$ is the amount of shear stress that can be transferred through a crack and $\sigma_{\mathrm{c} 1}$ is the average tensile stress in a concrete strut.

The average tensile stress of a strut can be estimated based on the crack spacing, which is assumed to be equal to 1.5 times the bond length (Marti et al., 1998), and the steel to concrete bond stress

55. $\sigma_{\mathrm{c} 1}=\frac{3}{16} \tau_{\mathrm{b}}$

When the contact forces develop at $45^{\circ}$ from the crack surface, $\tau_{\mathrm{cr}}$ can be evaluated on the basis of the proposal by Vecchio and Collins (1986) (refer to Figure 10(c))

56. $\tau_{\mathrm{cr}, 45^{\circ}}=\frac{\sqrt{f_{\mathrm{c}}}}{0 \cdot 31+\left[24 w_{\text {ini }} /\left(D_{\max }+16\right)\right]}$

where $w_{\text {ini }}$ is the initial crack width and $D_{\max }$ is the maximum aggregate diameter $(\mathrm{mm}) \quad\left(D_{\max }=0\right.$ for $\left.f_{\mathrm{c}}>60 \mathrm{MPa}\right)$.

The minimum shear stress that can be transferred through a crack corresponds to the case in which the direction of the principal compressive stress is parallel to the face of a crack (see Figure 10(c)). Based on the work of Randl (2013) this can be estimated as dow, $x$ is the dowelled steel strength in the $x$-direction, $\sigma_{\mathrm{s} z}$ is the steel stress in the $z$-direction and $f_{\mathrm{y}, \text { dow }, z}$ is the dowelled steel strength in the $z$-direction.

For other values of the angle $\theta_{\mathrm{cr}}-\theta, \tau_{\mathrm{cr}}$ can be calculated as (refer to Figure 10(c))

58. $\tau_{\mathrm{cr}}=\tau_{\mathrm{cr}, \min }+\sqrt{2} \sin \left(\theta_{\mathrm{cr}}-\theta\right)\left(\tau_{\mathrm{cr}, 45^{\circ}}-\tau_{\mathrm{cr}, \min }\right)$

This assumption is based on the fact that the amount of shear that can be transferred through a crack increases quite quickly as the stress field starts to rotate (Vecchio and Collins, 1986) and then stabilises as $\theta_{\text {cr }}$ and $\theta$ become close to perpendicular. After analysis of $77 \mathrm{RC}$ panels, the proposed law showed good agreement with the test results, although the authors acknowledge that future work is required to verify its general consistency.

The last remaining effectiveness factor from Equation 46 is $\eta_{\text {dow }}$, which takes into account the presence of the confining concrete struts. As previously mentioned, the enhanced concrete compressive strength along the region influenced by the dowelling was used to equilibrate the shear forces of the rebar (see Figure 6(c)). This means that this region of the concrete cannot be included in carrying any compressive stresses in the principal direction. This effect can be taken into account using

59. $\eta_{\text {dow }}=\frac{f_{\text {cc }}}{f_{\mathrm{c}}} \geq 1 \cdot 0$

It is import to emphasise that even in the case when the yield strength of the reinforcement is not reduced due to the dowelling (point $\mathrm{B}$ in Figure 8), the rebars will still move towards the concrete, inducing the formation of cracks and activating the confinement effects of the concrete, meaning that Equation 59 also needs to be applied in these cases.

\section{Strength of the undamaged struts}

The compressive strength of the undamaged struts is limited by the parameter $\eta_{\text {UDS }}$, which takes into account

the presence of the rebars in the concrete struts, governing the spalling failures (as defined in Equation 47) and limiting the in-plane strength of the concrete (adopted from Hars (2006))

$$
\text { 57. } \tau_{\mathrm{cr}, \min }=0 \cdot 2 \sqrt[3]{f_{\mathrm{c}}}+\left(\begin{array}{l}
0 \cdot 8 \text { if } f_{\mathrm{c}} \leq 35 \mathrm{MPa} \\
1.0 \text { if } f_{\mathrm{c}}>35 \mathrm{MPa}
\end{array}\right)\left[\left(f_{\mathrm{y}, \text { dow }, x}-\sigma_{\mathrm{s} x}\right) \rho_{x} \sin \theta_{\mathrm{cr}}+\left(f_{\mathrm{y}, \text { dow }, z}-\sigma_{\mathrm{sz} z}\right) \rho_{z} \cos \theta_{\mathrm{cr}}\right]
$$

where $\rho_{x}$ is the horizontal reinforcement ratio, $\rho_{z}$ is the vertical reinforcement ratio, $\sigma_{\mathrm{s} x}$ is the steel stress in the $x$-direction, $f_{\mathrm{y}}$, the presence of the dowelled reinforcement (as defined in Equation 59). 
It is proposed that $\eta_{\mathrm{UDS}}$ is calculated as

60.

$$
\begin{aligned}
\eta_{\mathrm{UDS}}= & s_{\mathrm{dow}} \min \left\{\frac{\max \left\{\begin{array}{c}
0 \\
\eta_{\mathrm{s}}-\left(4 c+2 \phi_{\mathrm{ext}}\right)
\end{array}\right\}}{b_{\mathrm{w}}}+\frac{\min \left\{\begin{array}{c}
b_{\mathrm{w}} \\
4 c+2 \phi_{\mathrm{ext}}
\end{array}\right\}}{b_{\mathrm{w}}}\left(1-\eta_{\mathrm{dow}} \delta_{\mathrm{s}}\right)\right. \\
& +\left(1-s_{\mathrm{dow}}\right) \min \left\{\frac{\max \left\{\begin{array}{c}
0 \\
b_{\mathrm{w}}-\left(4 c+2 \phi_{\mathrm{ext}}\right)
\end{array}\right\}}{b_{\mathrm{w}}}+\frac{\min \left\{\begin{array}{c}
b_{\mathrm{w}} \\
4 c+2 \phi_{\mathrm{ext}}
\end{array}\right\}}{b_{\mathrm{w}}}\left[1-\left(1-\sin \phi_{\mathrm{s}}\right) \delta_{\mathrm{s}}\right]\right.
\end{aligned}
$$

in which $\phi_{\mathrm{s}}$ is the angle of friction between the rebar surface and the surrounding concrete and $s_{\text {dow }}$ is the relative amount of undamaged struts affected by the dowelling.

The only difference between Equations 46 and 60 is the fact that the factor $\eta_{\tau}$ is now equal to one (since there are no cracks crossing the undamaged struts) and that, unlike the damaged struts, the undamaged struts are only partly affected by the dowelling. This can be seen in Figure 9(a), where the confining concrete region (marked by dashed lines) crosses the undamaged struts only in their top-right and the bottom-left. The relative width of concrete affected by the dowelling $\left(s_{\text {dow }}\right)$ can be expressed as a function of the total width of the undamaged struts.

Based on the geometrical consideration presented in Figure $9(\mathrm{~d}), s_{\text {dow }}$ can be estimated using

61. $\delta_{\mathrm{cc}}=\frac{\cos \left(\theta_{\mathrm{cr}}-\theta\right)}{s_{\mathrm{rm}}} \max \left\{\begin{array}{l}l_{\mathrm{dow}, x} \sin \theta \\ l_{\mathrm{dow}, z} \cos \theta\end{array}\right.$

62. $s_{\mathrm{dow}}=\frac{2 \delta_{\mathrm{cc}}}{1-s_{\tau}}$

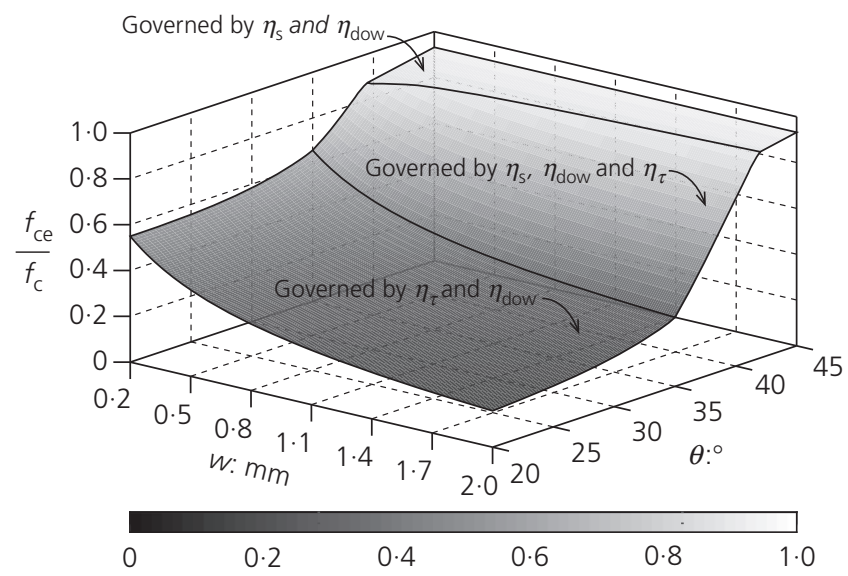

Figure 11. Representation of the failure criterion for the concrete compressive strength as a function of the stress field rotation and the crack opening at first yielding

\section{Governing parameters}

The mechanical model for the effective concrete compressive strength is quite complex and depends on a significant number of parameters (a possible strategy for solving the resulting set of equations is presented in the Appendix). However, the two parameters with the largest influence on the results are the width of the crack at the point of first yielding $\left(w_{\text {ini }}\right)$ and the ultimate angle of the principal concrete compressive stresses. Figure 11 gives a clear view on how these two parameters influence the concrete compressive strength effectiveness factor.

As shown in Figure 11, there are three different regions in the failure surface. The first corresponds to the situation in which the rotation of the stress field is quite limited (see Figure 12(a)). For these cases, the strength of the damaged and undamaged struts is governed by the presence of the spalling cracks $\left(\eta_{\mathrm{s}}\right)$ and the dowelling action $\left(\eta_{\text {dow }}\right)$. It can be seen that the width of the initial cracks does not influence the failure criterion. Stress field rotations, on the other hand, reduce the concrete compressive strength because the amount of undamaged struts affected by the dowel action of the reinforcement increases.

As the stress field continues to rotate, the strength of the damaged struts becomes governed by the presence of in-plane cracks $\left(\eta_{\tau}\right)$, while the strength of the undamaged struts remains dependent on the out-of-plane cracks $\left(\eta_{\mathrm{s}}\right)$, as shown in Figure 12(b). This corresponds to the second region of the

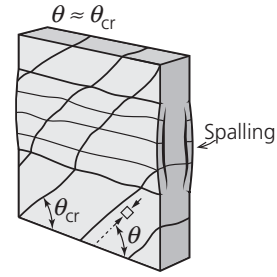

(a)

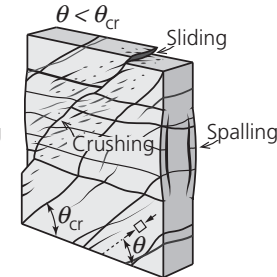

(b)

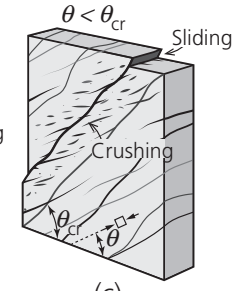

(c)
Figure 12. Potential failure mechanism of structural panels. (a) Spalling of the concrete cover in the case of small stress field rotation. (b) Spalling and combined crushing with sliding failure in the case of moderate stress field rotation. (c) Crushing and sliding of the concrete struts in the case of significant stress field rotation 
Table 1. Database of RC panels failing in shear

\begin{tabular}{|c|c|c|c|c|c|c|c|c|c|c|}
\hline No. & Reference & Specimen ID & $b_{\mathrm{w}}: \mathrm{mm}$ & $\phi_{x}: \mathrm{mm}$ & $\phi_{z}: \mathrm{mm}$ & $\rho_{x}: \%$ & $\rho_{z}: \%$ & $f_{\mathrm{c}}: \mathrm{MPa}$ & $f_{y x}: M P a$ & $f_{\mathrm{yz}}: \mathrm{MPa}$ \\
\hline 1 & Vecchio and Collins (1982) & PV4 & 70 & 3.43 & 3.43 & 1.06 & 1.06 & 27 & 242 & 242 \\
\hline 2 & & PV6 & 70 & $6 \cdot 31$ & $6 \cdot 31$ & $1 \cdot 79$ & 1.79 & 30 & 266 & 266 \\
\hline 3 & & PV10 & 70 & $6 \cdot 31$ & $4 \cdot 72$ & $1 \cdot 79$ & 1.00 & 15 & 276 & 276 \\
\hline 4 & & PV11 & 70 & $6 \cdot 31$ & $5 \cdot 39$ & $1 \cdot 79$ & $1 \cdot 31$ & 16 & 235 & 235 \\
\hline 5 & & PV12 & 70 & $6 \cdot 31$ & $3 \cdot 15$ & 1.79 & 0.45 & 16 & 469 & 269 \\
\hline 6 & & PV16 & 70 & 4.06 & 4.06 & 0.74 & 0.74 & 22 & 255 & 255 \\
\hline 7 & & PV19 & 70 & $6 \cdot 31$ & 3.99 & 1.79 & 0.71 & 19 & 458 & 299 \\
\hline 8 & & PV20 & 70 & $6 \cdot 31$ & 4.44 & 1.79 & 0.89 & 20 & 460 & 297 \\
\hline 9 & & PV21 & 70 & $6 \cdot 31$ & $5 \cdot 37$ & 1.79 & $1 \cdot 30$ & 20 & 458 & 302 \\
\hline 10 & & PV22 & 70 & $6 \cdot 31$ & $5 \cdot 83$ & 1.79 & $1 \cdot 52$ & 20 & 458 & 420 \\
\hline 11 & & PV23 & 70 & $6 \cdot 31$ & $6 \cdot 31$ & 1.79 & 1.79 & 21 & 518 & 518 \\
\hline 12 & & PV25 & 70 & $6 \cdot 31$ & $6 \cdot 31$ & 1.79 & 1.79 & 19 & 466 & 466 \\
\hline 13 & & PV27 & 70 & $6 \cdot 31$ & $6 \cdot 31$ & 1.79 & 1.79 & 21 & 442 & 442 \\
\hline 14 & & PV28 & 70 & $6 \cdot 31$ & $6 \cdot 31$ & 1.79 & 1.79 & 19 & 483 & 483 \\
\hline 15 & Vecchio et al. (1994) & PHS2 & 70 & 8.05 & $5 \cdot 72$ & $3 \cdot 23$ & 0.41 & 66 & 606 & 521 \\
\hline 16 & & PHS3 & 70 & 8.05 & $5 \cdot 72$ & $3 \cdot 23$ & 0.82 & 58 & 606 & 521 \\
\hline 17 & & PHS5 & 70 & 8.05 & $5 \cdot 72$ & $3 \cdot 23$ & 0.41 & 52 & 606 & 521 \\
\hline 18 & & PHS6 & 70 & 8.05 & $5 \cdot 72$ & $3 \cdot 23$ & 0.41 & 50 & 606 & 521 \\
\hline 19 & & PHS8 & 70 & 8.05 & $5 \cdot 72$ & $3 \cdot 23$ & 1.22 & 56 & 606 & 521 \\
\hline 20 & & PHS9 & 70 & 8.05 & $5 \cdot 72$ & $3 \cdot 23$ & 0.41 & 56 & 606 & 521 \\
\hline 21 & & PHS10 & 70 & 8.05 & $5 \cdot 72$ & $3 \cdot 23$ & $1 \cdot 22$ & 51 & 606 & 521 \\
\hline 22 & Marti and Meyboom (1992) & PP1 & 287 & $19 \cdot 54$ & $11 \cdot 28$ & 1.94 & 0.65 & 27 & 479 & 480 \\
\hline 23 & Vecchio and Chan (1990) & PC1A & 70 & $5 \cdot 72$ & $5 \cdot 72$ & 1.65 & 0.82 & 28 & 500 & 500 \\
\hline 24 & & PC4 & 70 & $5 \cdot 72$ & $5 \cdot 72$ & 1.65 & $0 \cdot 82$ & 25 & 260 & 260 \\
\hline 25 & Pang and Hsu (1995) & $\mathrm{A} 2$ & 178 & $16 \cdot 00$ & $16 \cdot 00$ & $1 \cdot 20$ & $1 \cdot 20$ & 41 & 462 & 462 \\
\hline 26 & & A3 & 178 & $19 \cdot 50$ & $19 \cdot 50$ & 1.78 & 1.78 & 42 & 446 & 446 \\
\hline 27 & & A4 & 178 & $25 \cdot 20$ & $25 \cdot 20$ & $2 \cdot 97$ & $2 \cdot 97$ & 42 & 469 & 469 \\
\hline 28 & & B1 & 178 & $16 \cdot 00$ & $11 \cdot 30$ & $1 \cdot 20$ & 0.60 & 45 & 462 & 444 \\
\hline 29 & & B2 & 178 & $19 \cdot 50$ & $16 \cdot 00$ & 1.78 & $1 \cdot 20$ & 44 & 446 & 462 \\
\hline 30 & & B3 & 178 & $19 \cdot 50$ & $11 \cdot 30$ & 1.78 & $0 \cdot 60$ & 45 & 446 & 444 \\
\hline 31 & & B4 & 178 & $25 \cdot 20$ & $11 \cdot 30$ & $2 \cdot 97$ & 0.60 & 45 & 469 & 444 \\
\hline 32 & & B5 & 178 & $25 \cdot 20$ & $16 \cdot 00$ & 2.97 & $1 \cdot 20$ & 43 & 469 & 462 \\
\hline 33 & & B6 & 178 & $25 \cdot 20$ & $19 \cdot 50$ & $2 \cdot 97$ & 1.78 & 43 & 469 & 446 \\
\hline 34 & Zhang and Hsu (1998) & VA1 & 178 & $11 \cdot 30$ & $11 \cdot 30$ & $1 \cdot 20$ & $1 \cdot 20$ & 95 & 445 & 445 \\
\hline 35 & & VA2 & 178 & $16 \cdot 00$ & $16 \cdot 00$ & $2 \cdot 40$ & $2 \cdot 40$ & 98 & 409 & 409 \\
\hline 36 & & VA3 & 178 & $19 \cdot 50$ & $19 \cdot 50$ & $3 \cdot 57$ & $3 \cdot 57$ & 95 & 455 & 455 \\
\hline 37 & & VA4 & 203 & $25 \cdot 20$ & $25 \cdot 20$ & $5 \cdot 23$ & $5 \cdot 23$ & 103 & 470 & 470 \\
\hline 38 & & VB1 & 178 & $16 \cdot 00$ & $11 \cdot 30$ & $2 \cdot 40$ & $1 \cdot 20$ & 98 & 409 & 445 \\
\hline 39 & & VB2 & 178 & $19 \cdot 50$ & $11 \cdot 30$ & $3 \cdot 57$ & $1 \cdot 20$ & 98 & 455 & 445 \\
\hline 40 & & VB3 & 178 & $25 \cdot 20$ & $11 \cdot 30$ & 5.96 & $1 \cdot 20$ & 102 & 470 & 445 \\
\hline 41 & & VB4 & 178 & $19 \cdot 50$ & $11 \cdot 30$ & $1 \cdot 78$ & 0.60 & 97 & 455 & 445 \\
\hline 42 & Hsu and Zhang (1997) & HB1 & 178 & $16 \cdot 00$ & $11 \cdot 30$ & $1 \cdot 20$ & $0 \cdot 60$ & 67 & 409 & 445 \\
\hline 43 & & HB3 & 178 & $19 \cdot 50$ & $11 \cdot 30$ & 1.78 & $0 \cdot 60$ & 67 & 447 & 445 \\
\hline 44 & & HB4 & 178 & $25 \cdot 20$ & $11 \cdot 30$ & $2 \cdot 98$ & 0.60 & 63 & 470 & 445 \\
\hline 45 & Kirschner (1986) & SE1 & 285 & $19 \cdot 50$ & $11 \cdot 30$ & $2 \cdot 91$ & 0.98 & 43 & 492 & 479 \\
\hline 46 & & SE6 & 285 & $19 \cdot 50$ & $11 \cdot 30$ & $2 \cdot 91$ & $0 \cdot 33$ & 40 & 492 & 479 \\
\hline 47 & Watanabe and Muguruma (1989) & OOR & 60 & $6 \cdot 00$ & $6 \cdot 00$ & 0.86 & 0.86 & 28 & 310 & 310 \\
\hline 48 & & $15 R$ & 60 & $6 \cdot 00$ & $6 \cdot 00$ & $0 \cdot 86$ & 0.86 & 28 & 310 & 310 \\
\hline 49 & & $30 R$ & 60 & $6 \cdot 00$ & $6 \cdot 00$ & $0 \cdot 86$ & 0.86 & 28 & 310 & 310 \\
\hline 50 & & $45 R$ & 60 & $6 \cdot 00$ & $6 \cdot 00$ & 0.86 & 0.86 & 28 & 310 & 310 \\
\hline 51 & & OOD & 60 & $7 \cdot 60$ & $7 \cdot 60$ & $0 \cdot 87$ & $0 \cdot 87$ & 28 & 318 & 318 \\
\hline 52 & & $30 \mathrm{D}$ & 60 & $7 \cdot 60$ & $7 \cdot 60$ & 0.86 & 0.87 & 28 & 318 & 318 \\
\hline 53 & & 45D & 60 & $7 \cdot 60$ & $7 \cdot 60$ & 0.87 & 0.87 & 28 & 318 & 318 \\
\hline 54 & & OODI & 60 & $7 \cdot 00$ & $7 \cdot 00$ & $1 \cdot 39$ & $1 \cdot 39$ & 31 & 294 & 294 \\
\hline 55 & & $22 \cdot 5 \mathrm{DI}$ & 60 & $7 \cdot 00$ & $7 \cdot 00$ & $1 \cdot 39$ & $1 \cdot 39$ & 31 & 294 & 294 \\
\hline 56 & & 45DI & 60 & $7 \cdot 60$ & $7 \cdot 60$ & $1 \cdot 30$ & $1 \cdot 30$ & 31 & 318 & 318 \\
\hline 57 & & 45DII & 60 & $7 \cdot 60$ & $7 \cdot 60$ & $2 \cdot 61$ & $2 \cdot 61$ & 31 & 318 & 318 \\
\hline 58 & & $45 \mathrm{PCl}$ & 60 & $5 \cdot 44$ & $5 \cdot 44$ & 0.77 & 0.77 & 30 & 1187 & 1187 \\
\hline 59 & & $45 \mathrm{PCI}$ & 60 & $5 \cdot 44$ & $5 \cdot 44$ & $1 \cdot 55$ & $1 \cdot 55$ & 30 & 1187 & 1187 \\
\hline 60 & & 45PCIII & 60 & $5 \cdot 44$ & $5 \cdot 44$ & 1.55 & 0.77 & 30 & 1187 & 1187 \\
\hline 61 & & 45PCIV & 60 & $5 \cdot 44$ & $5 \cdot 44$ & 1.55 & 0.77 & 45 & 1187 & 1187 \\
\hline
\end{tabular}


Table 1. Continued

\begin{tabular}{|c|c|c|c|c|c|c|c|c|c|c|}
\hline No. & Reference & Specimen ID & $b_{\mathrm{w}}: \mathrm{mm}$ & $\phi_{x}: \mathrm{mm}$ & $\phi_{z}: \mathrm{mm}$ & $\rho_{x}: \%$ & $\rho_{z}: \%$ & $f_{c}: M P a$ & $f_{y x}: M P a$ & $f_{y z}: M P a$ \\
\hline 62 & Kollegger and Mehlhorn (1990) & PK02 & 70 & $6 \cdot 50$ & $6 \cdot 50$ & 1.07 & 1.07 & 19 & 660 & 660 \\
\hline 63 & & PK04 & 70 & $6 \cdot 50$ & $6 \cdot 50$ & 1.07 & 1.07 & 20 & 660 & 660 \\
\hline 64 & & PK07 & 70 & $6 \cdot 50$ & $6 \cdot 50$ & 1.07 & 1.07 & 21 & 660 & 660 \\
\hline 65 & & EGE6F1 & 100 & $6 \cdot 50$ & $6 \cdot 50$ & 0.66 & 0.66 & 16 & 465 & 465 \\
\hline 66 & & EGE6F2 & 100 & $6 \cdot 50$ & $6 \cdot 50$ & 0.66 & 0.66 & 16 & 465 & 465 \\
\hline 67 & & EGE6F3 & 100 & $6 \cdot 50$ & $6 \cdot 50$ & 0.66 & 0.66 & 15 & 465 & 465 \\
\hline 68 & & EGE6F4 & 100 & $6 \cdot 50$ & $6 \cdot 50$ & 0.66 & 0.66 & 17 & 465 & 465 \\
\hline 69 & & EGE6F7 & 100 & $6 \cdot 50$ & $6 \cdot 50$ & 0.66 & 0.66 & 19 & 465 & 465 \\
\hline 70 & & EGE6F8 & 100 & $6 \cdot 50$ & $6 \cdot 50$ & 0.66 & 0.66 & 13 & 465 & 465 \\
\hline 71 & & EGE7F1 & 100 & $6 \cdot 50$ & $6 \cdot 50$ & 0.66 & 0.66 & 16 & 660 & 660 \\
\hline 72 & & EGE7F2 & 100 & $6 \cdot 50$ & $6 \cdot 50$ & 0.66 & 0.66 & 15 & 660 & 660 \\
\hline 73 & & EGE7F3 & 100 & $6 \cdot 50$ & $6 \cdot 50$ & 0.66 & 0.66 & 17 & 660 & 660 \\
\hline 74 & Schäfer et al. (1990) & $\# 2$ & 100 & $10 \cdot 00$ & $10 \cdot 00$ & $3 \cdot 14$ & $3 \cdot 14$ & 26 & 582 & 582 \\
\hline 75 & & \#6 & 100 & $10 \cdot 00$ & $10 \cdot 00$ & 1.57 & 1.57 & 26 & 582 & 582 \\
\hline 76 & André (1987) & KP1 & 140 & $12 \cdot 70$ & $12 \cdot 70$ & 2.03 & 1.02 & 25 & 430 & 430 \\
\hline 77 & & TP4A & 70 & $6 \cdot 35$ & $6 \cdot 35$ & 2.03 & 2.03 & 25 & 450 & 450 \\
\hline
\end{tabular}

failure criterion, which is dependent on the initial crack width (the wider the cracks, the larger the reduction in concrete compressive strength). The physical failure of the concrete struts in this region can occur due to spalling or crushing of the material.

As the stress field increases its rotation further, the amount of undamaged struts in the panel reduces and eventually becomes zero. This leads to the third stage of the failure criterion, when the strength of the entire panel is dependent only on the characteristics of the in-plane cracks $\left(\eta_{\tau}\right)$ (see Figure 12(c)). Once more, the influence of the initial crack width is quite pronounced and the failure mechanism of the concrete struts corresponds to crushing. Dowelling of the reinforcement affects the concrete strength of both the second and third regions of the failure surface. It has to be noted that when failure occurs by yielding of the reinforcement in both directions, the principal concrete compressive stresses do not reach $-f_{\text {ce. }}$.

\section{Experimental validation and comparison with available methods}

\section{Collected database}

In order to validate the assumptions of the proposed model, a database of 77 structural panels was collected (Table 1). This database contains the results of 12 separate experimental campaigns performed by various authors. The corresponding references and the basic geometrical and mechanical properties of the panels are provided in Table 1 .

The selected elements varied significantly in terms of concrete compressive strength (13-103 MPa), reinforcement ratios $(0 \cdot 33-$ $5.96 \%)$ and steel yield strength (235-1187 MPa) as well as the ratio of the reinforcement placed in two perpendicular directions (from $0 \cdot 11$ to $1 \cdot 00$ ). The size of the specimens varied from
$500 \mathrm{~mm}$ to $2510 \mathrm{~mm}$, while their thickness varied from $60 \mathrm{~mm}$ to $287 \mathrm{~mm}$. With respect to the loading conditions, most of the panels were subjected to pure shear (55 out of 77 specimens), some combined shear with compression (19 out of 77 specimens) and a few were loaded to shear and biaxial traction (three out of the 77 panels). The panels experienced different failure modes (concrete spalling, crushing or sliding) and while some failed due to weakening of the concrete, others failed due to yielded reinforcement in both directions.

\section{Comparison with test database}

In order to assess the accuracy of the presented approach and compare it with some of the existing strain-based approaches, the database shown in Table 1 was assessed using the elasticplastic stress field (EPSF) method (Fernández Ruiz and Muttoni, 2007), implementing the softening equation proposed by Vecchio and Collins (1986). Table 2 summarises the results of both analyses and gives the ultimate strength assessment for each approach. It can be seen that both approaches provide satisfactory accuracy. However, the proposed mechanical procedure shows a higher level of accuracy (average of 1.01 compared with $1 \cdot 11$ for the EPSF approach) and lower scatter of the results $(0 \cdot 12$ compared with $0 \cdot 15$ for EPSF). Additionally, it provides information on the governing failure modes, which matched those observed in the 77 test specimens.

The ratios of the measured to estimated strengths are also presented in Figure 13 as a function of four basic parameters the concrete compressive strength $f_{\mathrm{c}}$, the reinforcement ratio in the $x$-direction $\rho_{x}$, the reinforcement ratio in the $z$-direction $\rho_{z}$ and the steel strength in the $z$-direction (which was the weaker direction) $f_{\mathrm{yz}}$. Each of the plots shows a curve which gives the average value of the five nearest $\tau_{\text {test }} / \tau_{\text {model }}$ points (with respect to a given parameter) from the entire database. As shown in the figure, the proposed mechanical approach gave consistent results over the investigated domain and showed no clear 
Table 2. Results of the EPSF analysis and the mechanical model proposed in this paper

\begin{tabular}{|c|c|c|c|c|c|c|c|}
\hline No. & Reference & Specimen ID & $\tau_{\text {test }}: \mathrm{MPa}$ & $\tau_{\text {EPSF }}: \mathbf{k N}$ & $\tau_{\text {model }}: \mathbf{k N}$ & $\tau_{\text {test }} /, \tau_{\text {EPSF }}$ & $\tau_{\text {test }} / \tau_{\text {model }}$ \\
\hline 1 & Vecchio and Collins (1982) & PV4 & $2 \cdot 84$ & $2 \cdot 56$ & $2 \cdot 62$ & $1 \cdot 11$ & 1.08 \\
\hline 2 & & PV6 & 4.47 & 4.76 & $4 \cdot 81$ & 0.94 & 0.93 \\
\hline 3 & & PV10 & 3.97 & $3 \cdot 69$ & $3 \cdot 73$ & 1.08 & 1.06 \\
\hline 4 & & PV11 & $3 \cdot 56$ & $3 \cdot 59$ & $3 \cdot 63$ & 0.99 & 0.98 \\
\hline 5 & & PV12 & $3 \cdot 13$ & $2 \cdot 55$ & 3.05 & 1.23 & 1.03 \\
\hline 6 & & PV16 & $2 \cdot 14$ & 1.89 & 1.95 & $1 \cdot 13$ & $1 \cdot 10$ \\
\hline 7 & & PV19 & 3.96 & 3.73 & 4.01 & 1.06 & 0.99 \\
\hline 8 & & PV20 & $4 \cdot 26$ & $4 \cdot 22$ & $4 \cdot 46$ & 1.01 & 0.96 \\
\hline 9 & & PV21 & $5 \cdot 03$ & $5 \cdot 18$ & $5 \cdot 46$ & 0.97 & 0.92 \\
\hline 10 & & PV22 & $6 \cdot 07$ & $6 \cdot 39$ & $7 \cdot 11$ & 0.95 & 0.85 \\
\hline 11 & & PV23 & 8.88 & $7 \cdot 69$ & 8.09 & $1 \cdot 15$ & $1 \cdot 10$ \\
\hline 12 & & PV25 & $9 \cdot 13$ & $8 \cdot 39$ & $7 \cdot 58$ & 1.09 & $1 \cdot 20$ \\
\hline 13 & & PV27 & $6 \cdot 35$ & $6 \cdot 74$ & $7 \cdot 94$ & 0.94 & $0 \cdot 80$ \\
\hline 14 & & PV28 & $5 \cdot 61$ & $5 \cdot 89$ & $6 \cdot 56$ & 0.95 & 0.86 \\
\hline 15 & Vecchio et al. (1994) & PHS2 & $6 \cdot 66$ & $5 \cdot 18$ & $5 \cdot 21$ & $1 \cdot 29$ & $1 \cdot 28$ \\
\hline 16 & & PHS3 & $8 \cdot 10$ & $7 \cdot 67$ & $7 \cdot 92$ & 1.06 & 1.02 \\
\hline 17 & & PHS5 & $4 \cdot 81$ & 3.54 & 3.96 & $1 \cdot 36$ & 1.21 \\
\hline 18 & & PHS6 & $7 \cdot 62$ & $7 \cdot 30$ & $7 \cdot 80$ & 1.04 & 0.98 \\
\hline 19 & & PHS8 & $10 \cdot 84$ & $9 \cdot 53$ & $9 \cdot 91$ & $1 \cdot 14$ & 1.09 \\
\hline 20 & & PHS9 & $9 \cdot 16$ & $7 \cdot 52$ & $7 \cdot 87$ & $1 \cdot 22$ & $1 \cdot 16$ \\
\hline 21 & & PHS10 & $8 \cdot 25$ & $7 \cdot 57$ & $7 \cdot 82$ & 1.09 & 1.05 \\
\hline 22 & Marti and Meyboom (1992) & PP1 & 4.95 & $5 \cdot 11$ & 4.79 & 0.97 & 1.03 \\
\hline 23 & Vecchio and Chan (1990) & PC1A & $5 \cdot 61$ & $5 \cdot 84$ & $6 \cdot 05$ & 0.96 & 0.93 \\
\hline 24 & & PC4 & $4 \cdot 84$ & $5 \cdot 10$ & $5 \cdot 75$ & 0.95 & 0.84 \\
\hline 25 & Pang and Hsu (1995) & $\mathrm{A} 2$ & $5 \cdot 37$ & $5 \cdot 54$ & $6 \cdot 13$ & 0.97 & 0.88 \\
\hline 26 & & A3 & $7 \cdot 65$ & $7 \cdot 94$ & $8 \cdot 49$ & 0.96 & 0.90 \\
\hline 27 & & A4 & $11 \cdot 31$ & 11.91 & $14 \cdot 08$ & 0.95 & $0 \cdot 80$ \\
\hline 28 & & B1 & $3 \cdot 96$ & $3 \cdot 82$ & $4 \cdot 54$ & 1.04 & $0 \cdot 87$ \\
\hline 29 & & B2 & $6 \cdot 13$ & $6 \cdot 63$ & $7 \cdot 25$ & 0.92 & 0.85 \\
\hline 30 & & B3 & $4 \cdot 35$ & $4 \cdot 59$ & $4 \cdot 89$ & 0.95 & 0.89 \\
\hline 31 & & B4 & 5.06 & $5 \cdot 50$ & $5 \cdot 60$ & 0.92 & 0.90 \\
\hline 32 & & B5 & $7 \cdot 15$ & $8 \cdot 27$ & 8.03 & 0.86 & 0.89 \\
\hline 33 & & B6 & $9 \cdot 14$ & $9 \cdot 96$ & $10 \cdot 11$ & 0.92 & 0.90 \\
\hline 34 & Zhang and Hsu (1998) & VA1 & $6 \cdot 16$ & $5 \cdot 34$ & $6 \cdot 19$ & $1 \cdot 15$ & 0.99 \\
\hline 35 & & VA2 & $9 \cdot 73$ & $9 \cdot 84$ & $10 \cdot 62$ & 0.99 & 0.92 \\
\hline 36 & & VA3 & $15 \cdot 08$ & $16 \cdot 25$ & $16 \cdot 91$ & 0.93 & 0.89 \\
\hline 37 & & VA4 & $21 \cdot 42$ & 21.05 & $21 \cdot 36$ & 1.02 & 1.00 \\
\hline 38 & & VB1 & $7 \cdot 50$ & $7 \cdot 25$ & $7 \cdot 82$ & 1.03 & 0.96 \\
\hline 39 & & VB2 & $9 \cdot 14$ & $9 \cdot 32$ & 8.94 & 0.98 & 1.02 \\
\hline 40 & & VB3 & $9 \cdot 71$ & $10 \cdot 55$ & $10 \cdot 20$ & 0.92 & 0.95 \\
\hline 41 & & VB4 & $4 \cdot 86$ & 4.66 & $6 \cdot 28$ & 1.04 & $0 \cdot 77$ \\
\hline 42 & Hsu and Zhang (1997) & HB1 & $4 \cdot 32$ & $3 \cdot 63$ & $4 \cdot 41$ & $1 \cdot 19$ & 0.98 \\
\hline 43 & & HB3 & $4 \cdot 89$ & $4 \cdot 62$ & $6 \cdot 28$ & 1.04 & 0.97 \\
\hline 44 & & HB4 & $5 \cdot 33$ & $5 \cdot 84$ & $5 \cdot 85$ & 0.91 & 0.91 \\
\hline 45 & Kirschner (1986) & SE1 & $6 \cdot 77$ & $7 \cdot 52$ & $7 \cdot 32$ & 0.90 & 0.92 \\
\hline 46 & & SE6 & $3 \cdot 76$ & 3.92 & 3.96 & 0.96 & 0.95 \\
\hline 47 & Watanabe and Muguruma (1989) & OOR & $3 \cdot 14$ & $2 \cdot 66$ & $2 \cdot 72$ & $1 \cdot 18$ & $1 \cdot 15$ \\
\hline 48 & & $15 R$ & $3 \cdot 15$ & $2 \cdot 66$ & $2 \cdot 72$ & $1 \cdot 18$ & $1 \cdot 16$ \\
\hline 49 & & $30 R$ & $3 \cdot 13$ & $2 \cdot 66$ & $2 \cdot 72$ & $1 \cdot 18$ & $1 \cdot 15$ \\
\hline 50 & & $45 R$ & $3 \cdot 42$ & $2 \cdot 66$ & $2 \cdot 72$ & $1 \cdot 29$ & $1 \cdot 26$ \\
\hline 51 & & OOD & $2 \cdot 97$ & $2 \cdot 70$ & $2 \cdot 83$ & $1 \cdot 10$ & 1.05 \\
\hline 52 & & $30 D$ & $2 \cdot 56$ & $2 \cdot 70$ & $2 \cdot 82$ & 0.95 & 0.91 \\
\hline 53 & & $45 D$ & $2 \cdot 84$ & $2 \cdot 70$ & $2 \cdot 83$ & 1.05 & 1.00 \\
\hline 54 & & OODI & 4.96 & $4 \cdot 10$ & $4 \cdot 17$ & $1 \cdot 21$ & $1 \cdot 19$ \\
\hline 55 & & $22 \cdot 5 \mathrm{DI}$ & $5 \cdot 06$ & $4 \cdot 10$ & $4 \cdot 17$ & $1 \cdot 23$ & $1 \cdot 21$ \\
\hline 56 & & 45DI & 3.97 & $4 \cdot 15$ & $4 \cdot 21$ & 0.96 & 0.94 \\
\hline 57 & & 45D\| & $7 \cdot 61$ & $8 \cdot 29$ & $8 \cdot 35$ & 0.92 & 0.91 \\
\hline 58 & & $45 \mathrm{PCl}$ & $7 \cdot 78$ & $6 \cdot 55$ & $9 \cdot 26$ & $1 \cdot 19$ & 0.84 \\
\hline 59 & & $45 \mathrm{PCI}$ & $11 \cdot 72$ & $8 \cdot 39$ & 11.46 & $1 \cdot 40$ & 1.02 \\
\hline 60 & & 45PCIII & $9 \cdot 44$ & $7 \cdot 35$ & $9 \cdot 51$ & 1.29 & 0.99 \\
\hline 61 & & 45PCIV & $10 \cdot 63$ & 8.65 & $11 \cdot 12$ & $1 \cdot 23$ & 0.96 \\
\hline
\end{tabular}


Table 2. Continued

\begin{tabular}{|c|c|c|c|c|c|c|c|}
\hline No. & Reference & Specimen ID & $\tau_{\text {test }}: \mathrm{MPa}$ & $\tau_{\text {EPSF }}: \mathbf{k N}$ & $\tau_{\text {model }}: \mathbf{k N}$ & $\tau_{\text {test }} /, \tau_{\text {EPSF }}$ & $\tau_{\text {test }} / \tau_{\text {mode }}$ \\
\hline 62 & \multirow[t]{12}{*}{ Kollegger and Mehlhorn (1990) } & PK02 & $9 \cdot 12$ & $7 \cdot 40$ & $8 \cdot 39$ & 1.23 & 1.09 \\
\hline 63 & & PK04 & 8.91 & $6 \cdot 64$ & 8.75 & $1 \cdot 34$ & 1.02 \\
\hline 64 & & PK07 & 9.04 & $6 \cdot 79$ & 9.06 & $1 \cdot 33$ & 1.00 \\
\hline 65 & & EGE6F1 & 8.00 & 6.01 & $7 \cdot 28$ & $1 \cdot 33$ & $1 \cdot 10$ \\
\hline 66 & & EGE6F2 & $8 \cdot 10$ & 5.68 & $7 \cdot 37$ & 1.43 & $1 \cdot 10$ \\
\hline 67 & & EGE6F3 & 6.90 & $5 \cdot 17$ & $6 \cdot 72$ & $1 \cdot 34$ & 1.03 \\
\hline 68 & & EGE6F4 & $7 \cdot 20$ & $5 \cdot 71$ & $7 \cdot 69$ & $1 \cdot 26$ & 0.94 \\
\hline 69 & & EGE6F7 & $8 \cdot 50$ & $7 \cdot 32$ & 8.67 & $1 \cdot 16$ & 0.98 \\
\hline 70 & & EGE6F8 & $7 \cdot 35$ & $5 \cdot 23$ & 6.03 & 1.40 & $1 \cdot 22$ \\
\hline 71 & & EGE7F1 & $8 \cdot 20$ & $5 \cdot 89$ & $7 \cdot 28$ & $1 \cdot 39$ & $1 \cdot 13$ \\
\hline 72 & & EGE7F2 & $7 \cdot 70$ & $5 \cdot 32$ & $7 \cdot 00$ & 1.45 & $1 \cdot 10$ \\
\hline 73 & & EGE7F3 & $8 \cdot 70$ & $6 \cdot 47$ & $7 \cdot 93$ & $1 \cdot 35$ & $1 \cdot 10$ \\
\hline 74 & \multirow[t]{2}{*}{ Schäfer et al. (1990) } & $\# 2$ & $11 \cdot 78$ & $10 \cdot 94$ & 9.94 & 1.08 & $1 \cdot 18$ \\
\hline 75 & & $\# 6$ & $14 \cdot 07$ & $9 \cdot 30$ & $10 \cdot 93$ & $1 \cdot 51$ & $1 \cdot 29$ \\
\hline 76 & \multirow[t]{4}{*}{ André (1987) } & KP1 & $5 \cdot 62$ & 6.08 & $5 \cdot 79$ & 0.93 & 0.97 \\
\hline 77 & & TP4A & $8 \cdot 72$ & 8.00 & $9 \cdot 20$ & 1.09 & 0.95 \\
\hline Aver & & & & & & $1 \cdot 11$ & 1.01 \\
\hline Coet & & & & & & 0.15 & 0.12 \\
\hline
\end{tabular}

trends with respect to the four parameters, which is satisfactory. Figure 14 compares the accuracy of the presented approach with the EPSF method (Fernández Ruiz and Muttoni, 2007) implementing the softening equation proposed by Vecchio and Collins (1986) with respect to the stress field rotation. As can be seen, the mechanically-based model showed better accuracy for panels with small rotations when compared to the Vecchio and Collins (1986) approach but, most importantly, it also showed greater precision for panels with large rotations, which is relevant for the analysis of prestressed concrete beams. However, it should be noted that the number of panels that experienced significant stress field rotations was not large, and more specimens are required in order to consolidate these results.

\section{Detailed analysis and comparison with other models}

In order to compare the proposed mechanical procedure with existing strain-based approaches for estimating the effective concrete compressive strength, the ratio between the effective and cylinder concrete compressive strengths $\left(f_{\mathrm{ce}} / f_{\mathrm{c}}\right)$ of each panel is shown as a function of its average principal tensile strain $\left(\varepsilon_{1}\right)$ in Figure 15. The curve in the graph corresponds to the concrete compressive strength reduction factor according to Vecchio and Collins (1986). It can be seen that the results of the mechanical approach are consistent with the semiempirical equation established within the MCFT (Vecchio and Collins, 1986). Panels with smaller average tensile strains had smaller reduction factors and vice versa. However, unlike in the MCFT equations, the mechanical efficiency factor can never be equal to one. Even in panels with relatively lowstrength concrete $\left(f_{\mathrm{c}}<30 \mathrm{MPa}\right)$, the presence of reinforcement will always induce in-plane cracks and therefore reduce its effective compressive strength. This theoretical result is in agreement the semi-empirical formulas proposed by $\mathrm{Hsu}$ and Zhang (1997) and Kaufmann and Marti (1998).

\section{Conclusions}

The behaviour of panels subjected to in-plane forces was investigated and a model to describe their behaviour and potential failure modes was described. The main conclusions are as follows.

- The traditional description of the phenomenon of compression softening due to transverse cracking, by means of semi-empirical equations based on transverse strains, is simple to use but does not provide information on the actual failure mode or the parameters governing failure.

- A consistent approach to this issue should account for the different stages of behaviour, namely the uncracked state, the cracked state before yielding and the cracked state after yielding with the potential development of a secondary set of cracks.

- Each stage of behaviour may be governed by different failure modes. These are out-of-plane (spalling) failures, concrete crushing and crack sliding (after rotation of the principal stress direction). These failure modes can be consistently calculated.

- Dowelling of the bars has a significant influence on the response of the member. It allows the carrying of shear through the cracks but may induce spalling of the concrete cover. In general, the various shear-carrying actions are thus not independent.

- Dowelling of the rebars does not influence the axial strength capacity of the reinforcement. However, the doweling does affect the value of concrete compressive strength. 


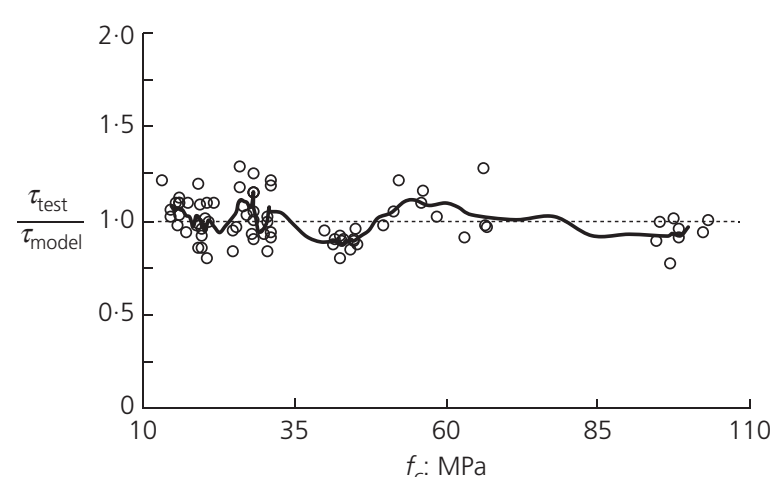

(a)

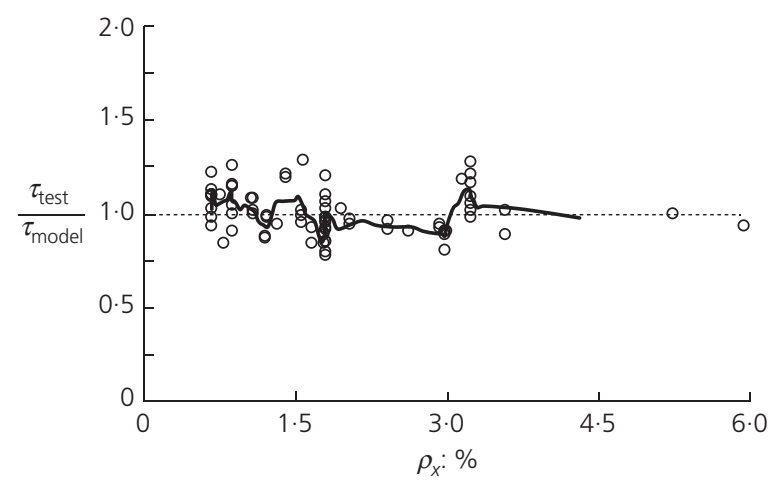

(b)

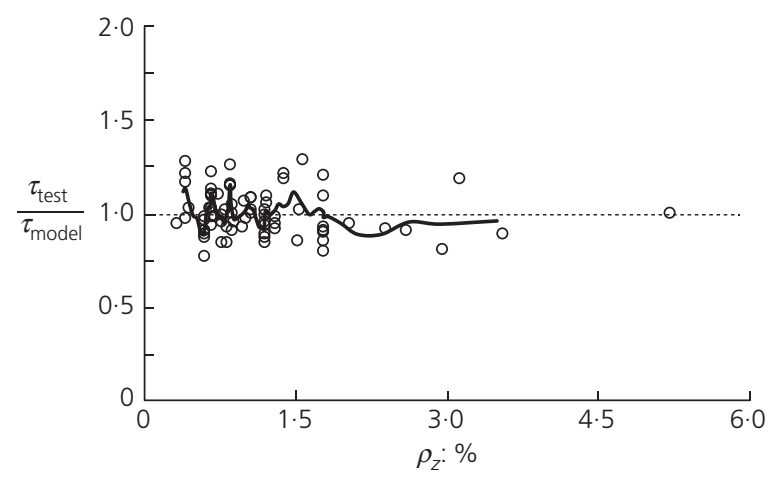

(c)

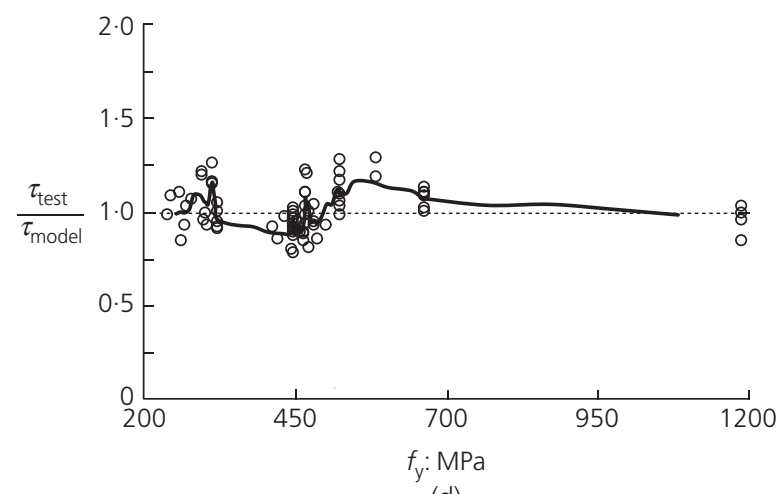

(d)

Figure 13. Shear strength prediction of the database as a function of: (a) concrete compressive strength; (b) steel yield strength; (c) horizontal reinforcement ratio; (d) vertical reinforcement ratio

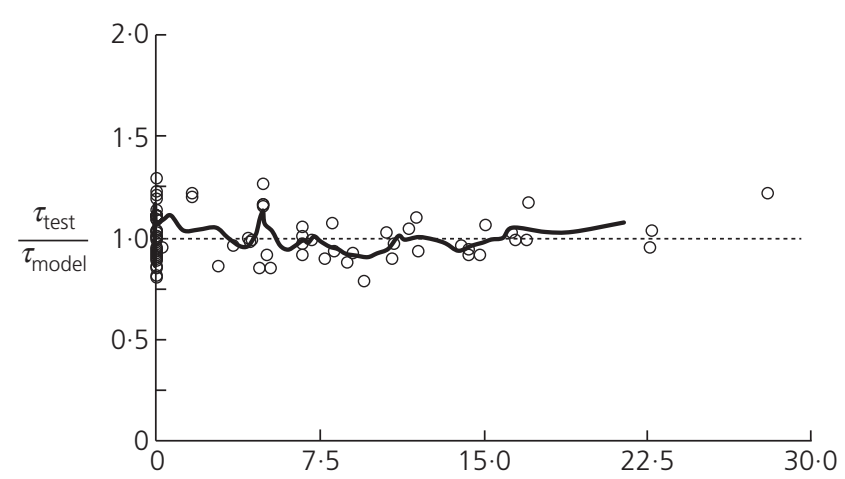

(a)

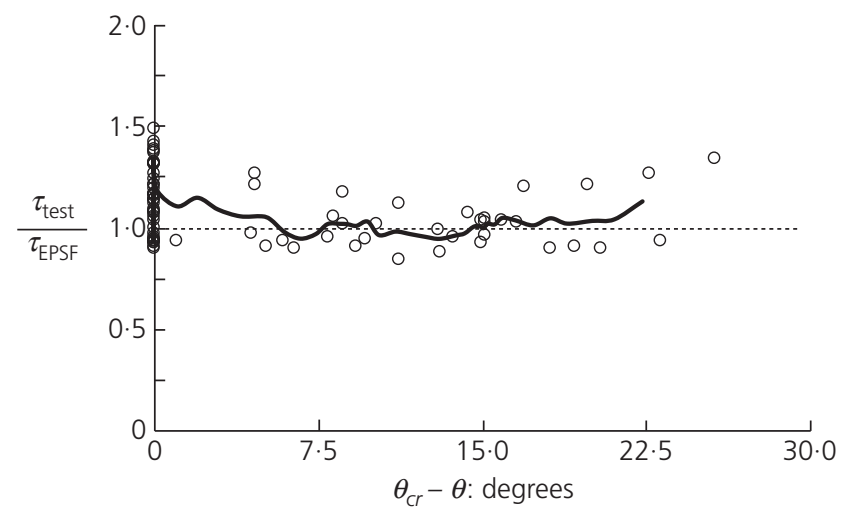

(b)

Figure 14. Shear strength prediction of the database using (a) the mechanical model presented in this paper and (b) the softening equation of Vecchio and Collins (1986) as a function of stress field rotation angle

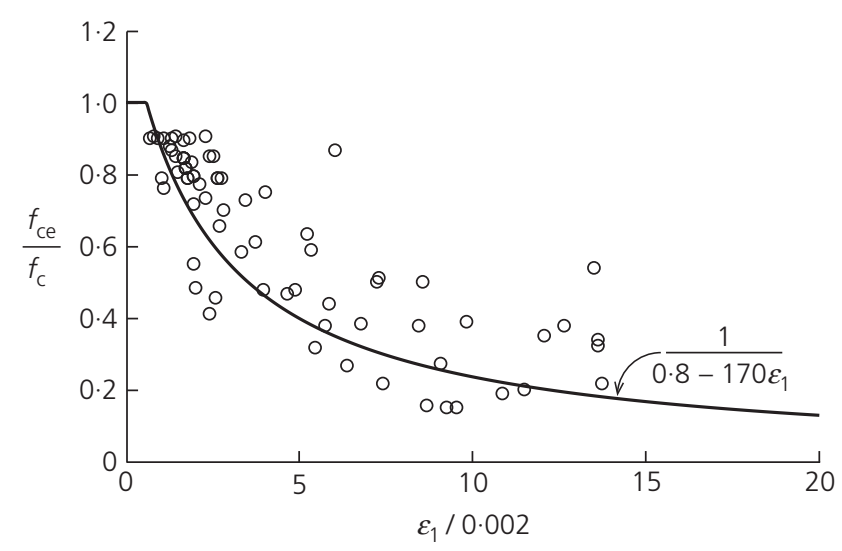

Figure 15. Calculated effective concrete compressive strength as a function of normalised principal tensile strains

A mechanical approach based on equilibrium and compatibility conditions can be developed, accounting for each stage of behaviour and its associated failure modes. A possible way of doing so was presented in this paper. 


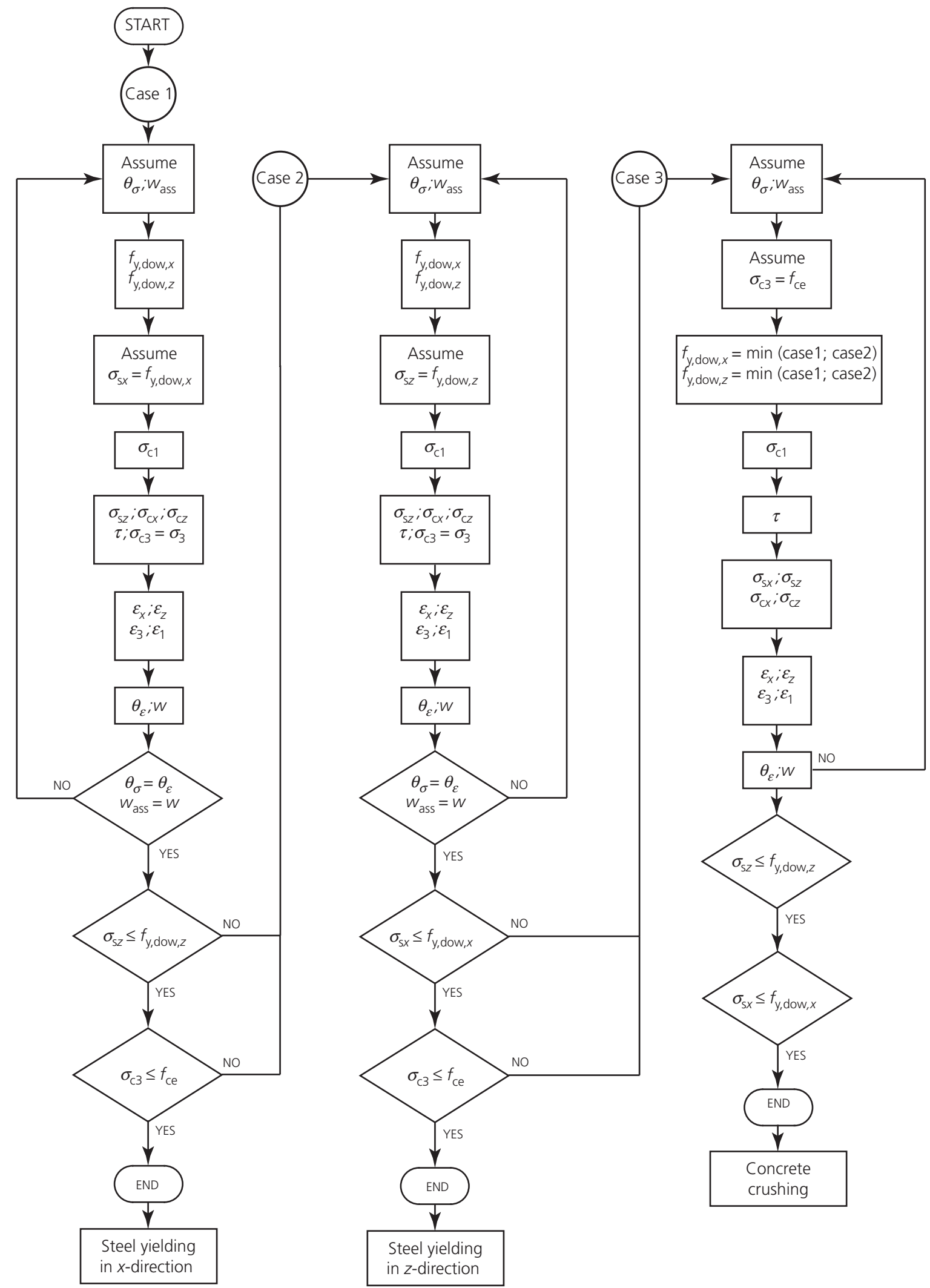

Figure 16. Solving procedure at the onset of yielding 
The results of the mechanical approach show good agreement with test results (and better than those of available semi-empirical formulas) and allow for a complete description of the load-deformation response. This is important not only for accuracy, but to provide designers with a clear physical understanding of failure mechanisms and how to enhance the behaviour of a member.

\section{Appendix: Numerical solving procedure}

In order to estimate the stress and strain states of a panel, it is first necessary to define the points that correspond to the limit cases of the three stages of behaviour (the elastic uncracked phase, the onset of yielding and failure). Once these points are known, full stress-strain curves can be produced by assuming that the stress field rotates linearly in between.

\section{Cracking of the panel}

First cracking can be directly calculated on the basis of Equations 2-7.

\section{Onset of yielding or early concrete crushing}

Finding the second characterising point in a panel's load history requires the use of an iterative procedure (as presented in Figure 16). The three potential cases that can determine the behaviour of a panel are

case 1 , which results in yielding of the reinforcement in the $x$-direction

- case 2, which results in yielding of the reinforcement in the $z$-direction

- case 3 , which results in concrete crushing prior to yielding of the reinforcement.

After assuming the direction of the principal concrete compressive stresses $\left(\theta_{\sigma}\right)$ and the final width of the initial cracks $\left(w_{\text {ass }}\right)$, it is possible to estimate the dowel strength of the reinforcement.

The average cracks spacing is assumed equal to be 1.5 times the bond length (Marti et al., 1998), which means that the average concrete tensile stress within the cracks is equal to

63. $\sigma_{\mathrm{c} 1}=\frac{3}{16} \tau_{\mathrm{b}}$

The principal concrete compressive stress inclination may be calculated using a Mohr circle (shown in Figure 4(b))

64. $\tan \theta_{\sigma}=\frac{\tau_{x z}}{\sigma_{\mathrm{c} 1}-\sigma_{\mathrm{c} x}}$
Assuming that the $x$ reinforcement yields the first $\sigma_{\mathrm{s} x}=f_{\mathrm{y}, \mathrm{dow}, x}$, equilibrium conditions give

65. $\sigma_{\mathrm{c} x}+\rho_{x} f_{\mathrm{y}, \mathrm{dow}, x}=v_{x}$

66. $\sigma_{\mathrm{c} z}+\rho_{z} \sigma_{\mathrm{s} z}=v_{z}$

67. $\tau_{x z}=v_{x z}$

Equations 63-67 present a system of five equations with five unknowns, which can be solved for $\tau_{x z}$, which can then be used to determine all the required stresses in concrete and steel. The applied stress rate in each direction is usually known, meaning that $v_{x}$ and $v_{z}$ can be expressed using $v_{x z}$. The results are checked by determining the strain state of the panel and making sure that the assumed principal stress angle $\left(\theta_{\sigma}\right)$ is equal to the principal strain angle $\left(\theta_{\varepsilon}\right)$ and by confirming that the assumed initial crack width ( $w_{\text {ass }}$ ) is equal to the calculated crack width $(w)$.

The average strains of the panel in the $x$ - and $z$-directions are equal to

68. $\varepsilon_{x}=\frac{f_{\mathrm{y} x, \mathrm{dow}}}{E_{\mathrm{s}}}-\frac{\tau_{\mathrm{b}} s_{\mathrm{rm} x}}{\phi_{x} E_{\mathrm{s}}}$

69. $\varepsilon_{z}=\frac{\sigma_{\mathrm{s} z}}{E_{\mathrm{s}}}-\frac{\tau_{\mathrm{b}} S_{\mathrm{rm} z}}{\phi_{z} E_{\mathrm{s}}}$

where $s_{\mathrm{rm} x}$ is the average crack spacing in the $x$-direction $(\mathrm{mm})$ and $s_{\mathrm{rm} z}$ is the average crack spacing in the $z$-direction $(\mathrm{mm})$.

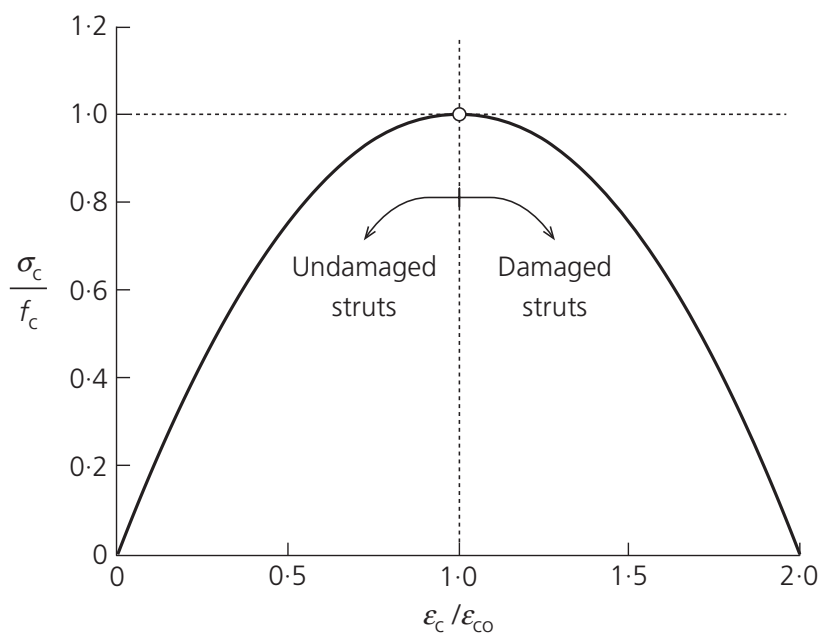

Figure 17. Stress-strain parabola for concrete compressive strength 
The principal concrete compressive strains can be determined by using the uniaxial stress-strain parabola (see Figure 17), assuming that the undamaged struts follow its ascending branch and that the damaged struts follow its descending branch

70. $\varepsilon_{3}=\varepsilon_{3 \mathrm{c}, \mathrm{DS}} s_{\tau}+\varepsilon_{3 \mathrm{c}, \mathrm{UDS}}\left(1-s_{\tau}\right)$

71. $\varepsilon_{3 \mathrm{c}, \mathrm{DS}}=\varepsilon_{0}\left(1+\sqrt{1-\sigma_{\mathrm{c} 3} / f_{\mathrm{c}}}\right)$
72. $\varepsilon_{3 \mathrm{c}, \mathrm{UDS}}=\varepsilon_{0}\left(1-\sqrt{1-\sigma_{\mathrm{c} 3} / f_{\mathrm{c}}}\right)$

73. $\varepsilon_{0}=2 f_{\mathrm{c}} / E_{\mathrm{c}} \approx-0.002$

Equations 68-70 define three points in the Mohr circle, which means that Figure 4(c) can be established and the principal compressive strain direction can be calculated

74. $\tan \theta_{\varepsilon}=\frac{\varepsilon_{x}-\varepsilon_{3}}{\varepsilon_{1}-\varepsilon_{x}}$

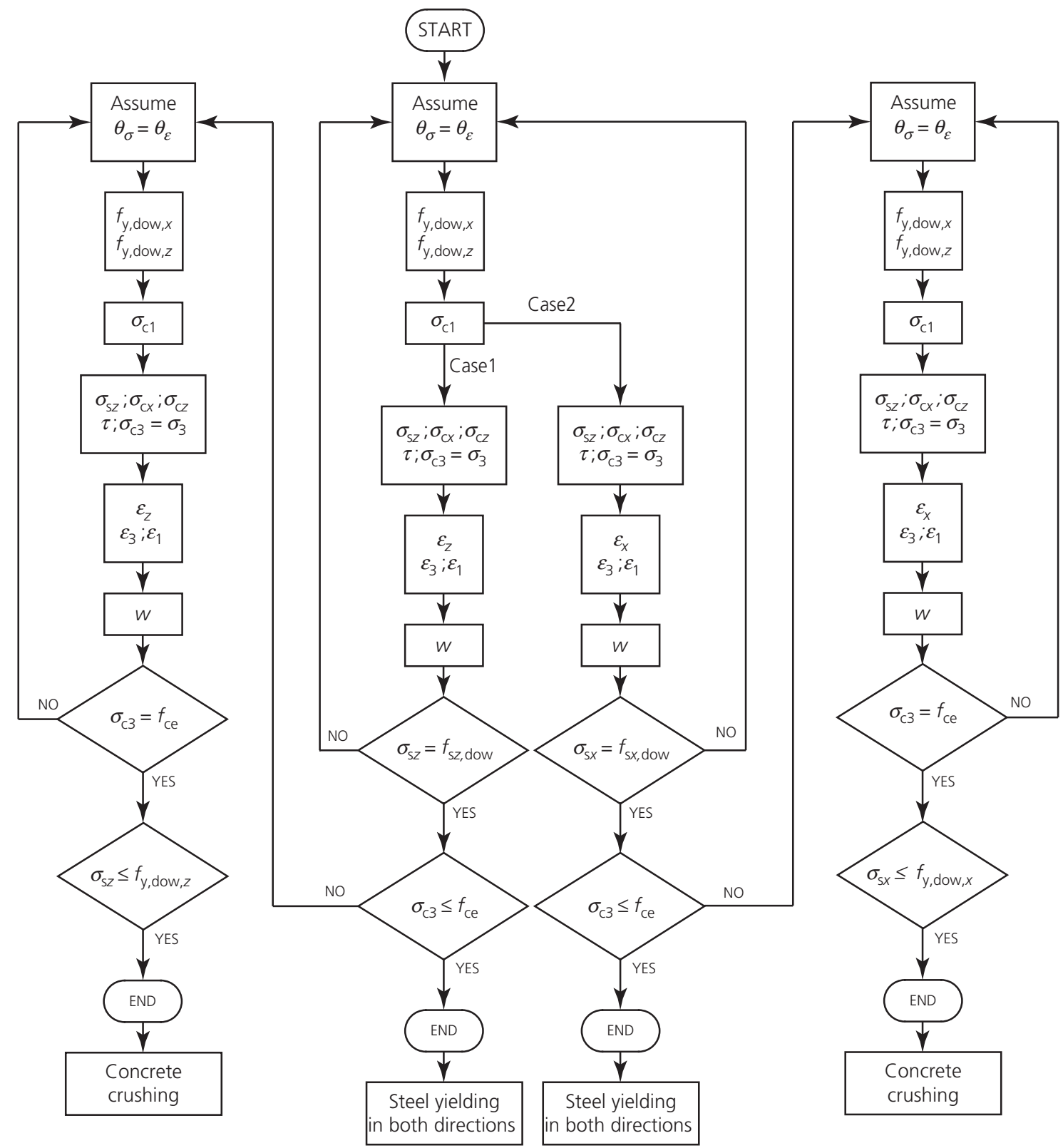

Figure 18. Solving procedure at failure 
Finally, it is possible to determine the initial crack opening using

75. $w_{\text {ini }}=s_{\mathrm{rm}}\left[\varepsilon_{1}-\left(\sigma_{\mathrm{cl}} / E_{\mathrm{c}}\right)\right]$

As indicated in Figure 16, it is now necessary to verify that the assumed stress state is respected, or try another case if the answer does not comply with this condition.

Case 2 is almost identical to case 1 , while case 3 is a bit simpler. The only difference between the solving procedure for case 1 and case 2 is in the fact that the vertical instead of the horizontal reinforcement is assumed to have reached yielding by the end of the second phase of the panel's load history. Apart from this, all the necessary validations and solving procedure are identical (see Figure 16).

The dowelled steel strength of the $x$-reinforcement according to case 1 is lower than that of case 3 , since the angle $\theta$ is higher for case 1 than for case 3 . Thus, the governing condition is crushing of the concrete struts instead of reinforcement yielding. In the same way, the dowelled steel strength of $z$-reinforcement according to case 2 is lower than that of case 3 . These two values for both dowelled steel strengths (of cases 1 and 2) are adopted for case 3, which is a slightly conservative simplification.

\section{Failure of the panel}

In order to determine the third (and final) characteristic point of the panel's load history, another iterative procedure needs to be applied. Looking at the scheme shown in Figure 18, it can be seen that, depending on the determining case from Figure 16, it is now possible to estimate the average strain in one direction ( $\varepsilon_{x}$ in case 2 or $\varepsilon_{z}$ in case 1$)$.

The direction of the principal compressive stresses is assumed to be parallel to the direction of the principal compressive strains. The secondary dowelling should only be applied on the reinforcement that did not yield during the previous phase ( $x$-direction in case 2 and $z$-direction in case 1). The additional dowelling should only be applied on the remaining steel stresses in the reinforcement that yields second, from the onset of the yielding of the direction of the first yielded reinforcement.

The stress field rotates until failure of the concrete or steel. The stress and strain transformations that were applied at the onset of yielding should be applied during this phase as well. At the end of the solving procedure, it is verified that the ultimate stress direction is lower than that at the onset of yielding.

\section{REFERENCES}

ACI (American Concrete Institute) (2008) ACI 318-08: Building code requirements for structural concrete and commentary. ACI, Farmington Hills, MI, USA.
André HMO (1987) Toronto/Kajima Study on Scale Effects in Reinforced Concrete Elements. $\mathrm{PhD}$ dissertation, University of Toronto, Toronto, ON, Canada.

Belarbi A and Hsu CTT (1995) Constitutive laws of softened concrete in biaxial tension-compression. ACI Structural Journal 92(5): 562-573.

CEN (European Committee for Standardization) (2004) Eurocode 2: Design of concrete structures - part 1-1: general rules and rules for buildings. CEN, Brussels, Belgium.

Fernández Ruiz M and Muttoni A (2007) On development of suitable stress fields for structural concrete. ACI Structural Journal 104(4) 495-502.

fib (International Federation for Structural Concrete) (2011) fib Model Code 2010, Final Draft. fib, Lausanne, Switzerland.

Hars E (2006) Zum Querkraftwiderstand von Stahl- und Spannbetonträgern mit dünnen Stegen. $\mathrm{PhD}$ dissertation, École Polytechnique Fédérale de Lausanne, IBETON, Lausanne, Switzerland (in German).

Hsu CTT and Zhang LX (1997) Nonlinear analysis of membrane elements by fixed-angle softened-truss model. ACI Structural Journal 94(5): 483-491.

Kaufmann W and Marti P (1998) Structural concrete: cracked membrane model. Journal of Structural Engineering 124(12): 1467-1475.

Kirschner U (1986) Investigating the Behaviour of Reinforced Concrete Shell Elements. $\mathrm{PhD}$ dissertation, University of Toronto, Toronto, ON, Canada.

Kollegger J and Mehlhorn G (1990) Experimentelle Untersuchungen zur Bestimmung der Druckfestigkeit des gerissenen Stahlbetons bei einer Querzugbeanspruchung. Deutscher Ausschuss für Stahlbeton, Berlin, Germany, Test report no. 413 (in German).

Marti P and Meyboom J (1992) Response of prestressed concrete elements to in-plane shear forces. ACI Structural Journal 89(5): 503-514.

Marti P, Alvarez M, Kaufmann W and Sigrist V (1998) Tension chord model for structural concrete. Structural Engineering International 8(4): 287-298.

Muttoni A (1989) Die Anwendbarkeit der Plastizitätstheorie in der Bemessung von Stahlbeton. PhD dissertation, ETHZ, Institut für Baustatik und Konstruktion, Zürich, Switzerland (in German).

Muttoni A, Burdet O and Hars E (2006) Effect of duct type on the shear strength of thin webs. ACI Structural Journal 103(5): 729-735.

Muttoni A, Fernández Ruiz M and Niketic F (2015) Design versus assessment of concrete structures using stress fields and strut-and-tie models. ACI Structural Journal 112(5): 605-616.

Nielsen MP and Hoang LC (2011) Limit Analysis and Concrete Plasticity, 3rd edn. CRC Press, Boca Raton, FL, USA.

Okamura H and Maekawa K (1991) Nonlinear Analysis and Constitutive Methods of Reinforced Concrete. University of Tokyo, Tokyo, Japan.

Pang XBD and Hsu CTT (1995) Behavior of reinforced concrete membrane elements in shear. ACI Structural Journal 92(6): 665-667.

Randl N (2013) Design recommendations for interface shear transfer in fib model code 2010. Structural Concrete 14(3): 230-241.

Rasmussen BH (1962) Strength of transversely loaded bolts and dowels cast into concrete. Proceedings of the Danish Society for Structural Science and Engineering 34(2): 39-55.

Schäfer K, Schelling G and Kuchler T (1990) Druck und Querzug in Bewehrten Betonelementen. Deutscher Ausschuss für Stahlbeton, Berlin, Germany, Test report no. 408 (in German).

Sorensen JH, Hoang LH, Olesen JF and Fischer G (2016) Catenary action in rebars crossing a casting joint loaded in shear. In Proceedings of the 11th fib International PhD Symposium in Civil Engineering, Tokyo, Japan (Maekawa K, Kasuga A and Yamazaki J (eds)). University of Tokyo, Tokyo, Japan, pp. 735-742. 
Tepfers R (1979) Cracking of concrete cover along anchored deformed reinforcing bars. Magazine of Concrete Research 31(106): 3-12, http://dx.doi.org/10.1680/macr.1979.31.106.3.

Vecchio FJ (2000) Disturbed stress field model for reinforced concrete: formulation. Journal of the Structural Division ASCE 126(9): 1070-1077.

Vecchio FJ and Chan CCL (1990) Reinforced concrete membrane elements with perforations. ASCE Journal of Structural Engineering 116(9): 2344-2360.

Vecchio FJ and Collins MP (1982) Response of Reinforced Concrete to In-Plane Shear and Normal Stresses. Department of Civil Engineering, University of Toronto, Toronto, ON, Canada.

Vecchio FJ and Collins MP (1986) The modified compression-field theory for reinforced concrete elements subjected to shear. ACI Structural Journal 83(2): 219-231.
Vecchio FJ, Collins MP and Aspiotis J (1994) High-strength concrete elements subjected to shear. ACI Structural Journal 91(4): 423-433.

Vintzeleou E and Tassios TP (1990) Eccentric dowels loaded against core of concrete sections. Journal of Structural Engineering 116(10): 2621-2633.

Watanabe $\mathrm{F}$ and Muguruma $\mathrm{H}$ (1989) Ultimate strength and deformations of RC panel. ASCE Structural Congress: Proceedings of Sessions Related to Structural Design Analysis and Testing, San Francisco, CA, USA. American Society of Civil Engineers, New York, NY, USA, pp. 31-38.

Zhang IX and Hsu TTC (1998) Behavior and analysis of $100 \mathrm{MPa}$ concrete membrane elements. Journal of Structural Engineering 124(1): $24-34$.

\section{How can you contribute?}

To discuss this paper, please submit up to 500 words to the editor at journals@ice.org.uk. Your contribution will be forwarded to the author(s) for a reply and, if considered appropriate by the editorial board, it will be published as a discussion in a future issue of the journal. 